\title{
Traducción de la sentencia de la Corte Internacional de Justicia en el caso Cuestión de delimitación de la plataforma continental entre Nicaragua y Colombia más allá de las 200 millas náuticas desde la costa nicaragüense (Nicaragua c. Colombia). Excepciones preliminares
}

\author{
Ricardo Abello Galvis*, Walter Arévalo Ramírez **, \\ María Alejandra Gómez ${ }^{* * *}$, Andrés Sarmiento Lamus ${ }^{+}$ \\ y Giovanny Vega Barbosa ${ }^{++}$
}

* Profesor principal de Derecho Internacional Público de la Facultad de Derecho de la Universidad del Rosario (Bogotá, Colombia); miembro de la Corte Permanente de Arbitraje (CPA) (2014-2019); M/Phil en Derecho Internacional y Relaciones Internacionales del Instituto de Altos Estudios Internacionales de Ginebra (IUHEI); estudiante de Doctorado en Ciencias Jurídicas de la Pontificia Universidad Javeriana; director/editor del ACDI Anuario Colombiano de Derecho Internacional; expresidente de la Academia Colombiana de Derecho Internacional (ACCOLDI); asociado del Instituto Hispano Luso Americano de Derecho Internacional (IHLADI). Correo electrónico: ricardo.abello@urosario.edu.co ** Profesor de Derecho Internacional Público de la Facultad de Derecho de la Universidad del Rosario (Bogotá, Colombia); LLM (Master of Laws) en Derecho Internacional; asistente de investigación de la Stetson University College of Law (2014); especialista en Derecho Constitucional; abogado y politólogo (cum laude); investigador del Grupo de Investigación de Derecho Internacional de la Facultad de Jurisprudencia de la Universidad del Rosario; estudiante de Doctorado en Derecho de la Universidad del Rosario; director de la Red Latinoamericana de Revistas de Derecho Internacional (Relaredi.org). Correo electrónico: walter.arevalo@urosario.edu.co

*** Estudiante de Jurisprudencia de la Universidad Colegio Mayor de Nuestra Señora del Rosario; miembro del Observatorio de Derecho Internacional del ACDI; pasante en la Misión de Colombia ante las Naciones Unidas en Ginebra durante el período 2015-I; asistente jurídica en la firma Cremades \& Calvo-Sotelo Abogados. Correo electrónico: malegozu@gmail.com

+ Profesor e investigador de la Universidad Sergio Arboleda en Derecho Internacional Público; candidato a Doctor ( $\mathrm{PhD}$ candidate), Universidad de Leiden (Países Bajos); estudios avanzados de Maestría (LLM Adv.) en Derecho Internacional Público, Universidad de Leiden; miembro de la Academia Colombiana de Derecho Internacional. Correo electrónico: andres.sarmiento@usa.edu.co

++ Abogado de la Universidad del Rosario; profesor titular de la cátedra de Derecho Internacional Público de la Facultad de Jurisprudencia de la Universidad del Rosario. Correo electrónico: giovanny.vega@urosario.edu.co 
Nota: a continuación, se presenta una traducción no oficial al idioma español del texto de la sentencia de excepciones preliminares proferida por la Corte Internacional de Justicia, el 17 de marzo de 2016, en el caso Cuestión de delimitación de la plataforma continental entre Nicaragua y Colombia más allá de las 200 millas náuticas desde la costa nicaragüense (Nicaragua c. Colombia). El texto original de la sentencia puede ser consultado en la página web de la Corte, en la siguiente dirección: http:/ / www.icj-cij.org. La presente traducción es exclusivamente para fines de divulgación y no tiene carácter oficial. No existe una versión oficial en español de las sentencias de la Corte, estas se emiten solo en sus idiomas oficiales, los cuales son, según el artículo 39-1 del Estatuto, el francés y el inglés. Además, según lo ordenado en el párrafo 2 del mismo artículo, en cada sentencia la Corte determina cuál es el idioma en el cual hace fe. En el caso de la sentencia del 17 de marzo de 2016 sobre Presuntas violaciones de derechos soberanos y espacios marítimos en el mar Caribe, este idioma es el inglés. En el caso de la sentencia del 17 de marzo de 2016 sobre Cuestión de delimitación de la plataforma continental entre Nicaragua y Colombia más allá de las 200 millas náuticas desde la costa nicaragüense, este idioma es el francés. Si bien la sentencia sobre delimitación más allá de las 200 millas náuticas corresponde al caso 154 en la Lista General de la Corte, y la sentencia sobre presuntas violaciones de derechos soberanos y espacios marítimos corresponde al caso 155 en la Lista General de la Corte, este volumen del Anuario Colombiano de Derecho Internacional presenta las traducciones de las mencionadas sentencias siguiendo el orden que la Corte estableció en las audiencias orales del 17 de marzo de 2016. Por razones de espacio, no es posible incluir aquí el texto integral de las opiniones individuales y disidentes que algunos jueces decidieron añadir a cada sentencia. Sin embargo, al final de cada traducción de sentencia, se incluyó también la traducción de los resúmenes de las opiniones de los jueces, preparados por la Secretaría de la Corte. 


\section{Tabla de contenido}

Cronología del procedimiento

Parágrafos

I. Introducción

II. Primera excepción preliminar

III. Tercera excepción preliminar

1. El principio res judicata

2. La decisión adoptada por la Corte en su fallo del 19 de noviembre de 2012

3. Aplicación del principio res judicata en el asunto

IV. Cuarta excepción preliminar

V. Segunda excepción preliminar

VI. Quinta excepción preliminar

1. Excepción preliminar frente a la admisibilidad de la primera pretensión de Nicaragua

2. Excepción preliminar de admisibilidad contra la segunda pretensión de Nicaragua 


\section{Corte Internacional de Justicia Año 2016}

\section{6}

\section{7 de marzo}

\section{Lista General}

$\mathrm{N}^{\mathrm{o}} 154$

\section{Cuestión de delimitación de la plataforma continental entre Nicaragua y Colombia más allá de las 200 millas náuticas desde la costa nicaragüense (Nicaragua c. Colombia) Excepciones preliminares}

Primera excepción preliminar de Colombia.

Argumentos de Colombia - La Corte carece de jurisdicción ratione temporis bajo el Pacto de Bogotá - Denuncia del Pacto bajo el artículo LVI - Efecto inmediato de la notificación de la denuncia.

Argumentos de Nicaragua - Mientras que el tratado se encuentre en vigor, el articulo XXXI del Pacto otorga la competencia a la Corte de acuerdo con lo señalado en el artículo LVI - El Pacto sigue siendo vinculante para las partes durante un año contado a partir de la fecha en que se notifique su denuncia - La Corte es competente ratione temporis en la medida en que la demanda de Nicaragua fue presentada antes de que se cumpliera el año de la notificación de la denuncia presentada por Colombia.

Análisis de la Corte - Fecha crítica para determinar la jurisdicción - Efectos de la denuncia establecida por el primer párrafo del artículo LVI - Cuestión de si el segundo párrafo del artículo LV I altera los efectos del primerpárrafo - Segundo párrafo confirma que los iniciados antes del aviso de la denuncia pueden continuar sin perjuicio de esa denuncia - Procedimientos iniciados durante el período de un año son procedimientos iniciados mientras el Pacto estaba vigente - La interpretación de Colombia conllevaría que la mayoría de los artículos del Pacto perdieran efecto mientras el Pacto está vigente - La interpretación de Colombia es inconsistente con el objeto y fin del Pacto - La interpretación de Colombia no es necesaria para dar effet utile al segundo párrafo del artículo LV I - La primera excepción preliminar de Colombia es rechazada.

La tercera excepción preliminar de Colombia según la cual la Corte carece de jurisdicción porque la demanda de Nicaragua no la permite la res judicata. 
La excepción caracterizada por la Corte como excepción a la admisibilidad.

Argumentos de Colombia - La primera pretensión de Nicaragua en su demanda de 2013 reitera su pretensión contenida en la pretensión final I(3) de 2012 relativa a la delimitación de la plataforma continental más allá de las 200 millas náuticas desde la costa de Nicaragua - En la decisión de 2012, esa pretensión fue declarada admisible pero no rechazada en el fondo - La primera pretensión no la permite la res judicata - La segunda pretensión solicita a la Corte declarar principios y reglas de derecho internacional que determinan los derechos y deberes de los dos Estados en el área relevante a la espera de delimitación - La segunda pretensión de Nicaragua está ligada a la primera y tampoco la permite la res judicata.

Argumentos de Nicaragua - La decisión de la Corte en el subparágrafo 3 de la cláusula operativa de la decisión de 2012 no constituye un rechazo sobre el fondo de la pretensión para una delimitación de la plataforma - La decisión de 2012 de la Corte se basó en el hecho de que Nicaragua no ha completado su entrega a la Comisión de Limites de la Plataforma Continental - Desde ese momento Nicaragua ha cumplido con su obligación del artículo 76, párrafo 8, de la Convemar - Cláusula operativa de la decisión de 2012 no toma posición sobre la delimitación de la plataforma continental más allá de las 200 millas náuticas - La Corte no está impedida para conocer la pretensión de Nicaragua para dicha delimitación en su demanda de 2013.

Análisis de la Corte - Principio res judicata - Finalidad de una decisión adoptada en un asunto particular - Identidad entre las partes, objeto y base legal Identidad entre pretensiones sucesivas no es suficiente - Necesidad de determinar en qué medida la primera pretensión ha sido decidida - Determinación de lo cubierto por la res judicata - Significado de la cláusula operativa debe ser establecido por referencia a las razones de la decisión.

Contenido y alcance del subparágrafo 3 de la cláusula operativa de la decisión de 2012 - Significado atribuido a la palabras "nopuede aceptar" - Revisión de las razones de la decisión en las sección IV de la decisión de 2012 - El hecho de que Colombia no sea parte de la Convemar no exime a Nicaragua de su obligación bajo el artículo 76 de la Convemar - Al momento de la decisión de 2012, Nicaragua solo había entregado 'información preliminar' a la CLPC - Decisión de la Corte en el parágrafo 129 de la decisión de 2012 - La Corte no decidió si tenía derecho a una plataforma continental más allá de las 200 millas náuticas desde su costa - La pretensión de Nicaragua en la pretensión final I(3) de 2012 no fue aceptada porque no habia cumplido aún con dicha obligación de acuerdo con elpárrafo 8 del artículo 76 de la Convemar - Cualquier delimitación está condicionada al cumplimiento de esta obligación.

Aplicación del principio res judicata en este asunto - Nicaragua presentó información 'final' a la CLPC en 2013 - Cumplimiento de la condición impuesta en la 
decisión de 2012 - La Corte no está impedida por la res judicata de decidir respecto de la demanda de Nicaragua - La tercera excepción preliminar de Nicaragua es rechazada.

La cuarta excepción preliminar de Colombia según la cual la Corte carece jurisdicción sobre una pretensión que es un intento de apelar y revisar la decisión de 2012 - Nicaragua no solicita a la Corte revisar la decisión de 2012, tampoco ba formulado su demanda como una 'apelación' - La cuarta excepción preliminar de Colombia es infundada y, por lo tanto, es rechazada.

La segunda excepción preliminar de Colombia según la cual la decisión de 2012 no confiere jurisdicción continua - La jurisdicción ya ha sido establecida con base en el articulo XXXI del Pacto - No hay necesidad de considerar si una base adicional de jurisdicción existe - No bay fundamento para que la Corte se pronuncie sobre la segunda excepción preliminar de Colombia.

Quinta excepción preliminar de Colombia.

Cuestión de la inadmisibilidad de la primera pretensión de Nicaragua - Si la recomendación de la CLPC es un prerrequisito para que la Corte delimite la plataforma continental más allá de las 200 millas náuticas - Rol y función de la CLPC - Delimitación de la plataforma continental es distinta a la delineación de sus límites exteriores - Delimitación de la plataforma continental más allá de las 200 millas náuticas puede efectuarse independientemente de la recomendación de la CLPC - La recomendación no es un prerrequisito - Excepción preliminar sobre la admisibilidad de la primera pretensión de Nicaragua es rechazada - Cuestión de la inadmisibilidad de la segunda pretensión de Nicaragua - La segunda pretensión no tiene relación con la presente controversia entre las partes - Excepción preliminar sobre la admisibilidad de la segunda pretensión de Nicaragua es aceptada. 


\section{Sentencia}

Presentes: presidente ABRAHAM, vicepresidente YUSUF, jueces OWADA, TOMKA, BENNOUNA, CANCADO TRINDADE, GREENWOOD, XUE, DONOGHUE, GAJA, SEBUTINDE, BHANDARI, ROBINSON, GEVORGIAN; jueces ad hOc BROWER, SKOTNIKOV; secretario COUVREUR.

En el asunto relativo a la cuestión de delimitación de la plataforma continental entre Nicaragua y Colombia más allá de las 200 millas náuticas desde la costa nicaragüense,

entre

la República de Nicaragua,

representada por

S. E. Sr. Carlos José Argüello Gómez, Embajador de la República de Nicaragua ante el Reino de los Países Bajos,

como agente y abogado;

Sr. Vaughan Lowe, Q.C., antiguo profesor Chichele, Derecho Internacional Público, Universidad de Oxford, miembro asociado del Institut de Droit International,

Sr. Alex Oude Elferink, director delegado, Netherlands Institute for the Law of the Sea, Universidad de Utrecht,

Sr. Alain Pellet, profesor de la Universidad Paris Ouest, Nanterre La Défense, antiguo miembro y presidente de la Comisión de Derecho Internacional, miembro asociado del Institut de Droit International,

Sr. Antonio Remiro Brotóns, profesor de Derecho Internacional, Universidad Autónoma, Madrid, miembro del Institut de Droit International, como consejeros y abogados;

Sr. César Vega Masís, Director de Asuntos Jurídicos, Soberanía y Territorio, Ministerio de Asuntos Exteriores,

Sr. Walner Molina Pérez, consultor jurídico, Ministerio de Relaciones Exteriores, 
Sr. Julio César Saborio, consultor jurídico, Ministerio de Relaciones Exteriores,

como consejeros;

Sr. Edgardo Sobenes Obregón, consejero, Embajada de Nicaragua en el Reino de los Países Bajos,

Sra. Claudia Loza Obregón, Primera Secretaria, Embajada de Nicaragua en el Reino de los Países Bajos,

Sr. Benjamín Samson, candidato a Doctor (PhD), Centro de Derecho Internacional de Nanterre (CEDIN), Universidad Paris Ouest, Nanterre La Défense,

Sra. Gimena González,

como consejero asistente;

Sra. Sherly Noguera de Argüello, Cónsul General de la República de Nicaragua,

como administradora,

$y$

la República de Colombia

representada por

S. E. Sra. María Ángela Holguín Cuéllar, Ministra de Relaciones Exteriores, Hon. Sra. Aury Guerrero Bowie, Gobernadora del Archipiélago de San Andrés, Providencia y Santa Catalina,

S. E. Sr. Francisco Echeverri Lara, Viceministro de Asuntos Multilaterales, Ministerio de Relaciones Exteriores,

como autoridades nacionales;

S. E. Sr. Carlos Gustavo Arrieta Padilla, antiguo juez del Consejo de Estado de Colombia, antiguo Procurador General de la Nación y antiguo Embajador de Colombia ante el Reino de los Países Bajos, 
como agente;

S. E. Sr. Manuel José Cepeda Espinosa, antiguo presidente de la Corte Constitucional colombiana, antiguo delegado permanente de Colombia ante la Unesco y antiguo Embajador de Colombia ante la Confederación Suiza, como coagente;

Sr. W. Michael Reisman, profesor McDougal de Derecho Internacional en la Facultad de Derecho de Yale, miembro del Institut de Droit International,

Sr. Rodman R. Bundy, antiguo avocat à la Cour d'appel de Paris, miembro de la barra de Nueva York, Eversheds LLP, Singapore,

Sir Michael Wood, KCMG, miembro de la Barra de Inglaterra y Gales, miembro de la Comisión de Derecho Internacional,

Sr. Tulio Treves, miembro del Institut de Droit International, consultor sénior en Derecho Internacional Público, Curtis, Mallet-Prevost, Colt \& Mosle LLP, Milán, profesor, Universidad de Milán,

Sr. Eduardo Valencia-Ospina, miembro de la Comisión de Derecho Internacional, Presidente de la Sociedad Latinoamericana de Derecho Internacional,

Sr. Matthias Herdegen, Dr. h.c., profesor de Derecho Internacional, Director del Instituto de Derecho Internacional de la Universidad de Bonn,

como consejeros y abogados;

S. E. Sr. Juan José Quintana Aranguren, Embajador de Colombia ante el Reino de los Países Bajos, representante permanente de Colombia ante la Organización para la Prohibición de Armas Químicas, antiguo representante permanente de Colombia ante las Naciones Unidas en Ginebra,

S. E. Sr. Andelfo García González, Embajador de la República de Colombia ante el Reino de Tailandia, profesor de Derecho Internacional, antiguo Viceministro de Relaciones Exteriores,

Sra. Andrea Jiménez Herrera, consejera, Embajada de la República de Colombia ante el Reino de los Países Bajos,

Sra. Lucía Solano Ramírez, Segunda Secretaria, Embajada de la República de Colombia ante el Reino de los Países Bajos,

Sr. Andrés Villegas Jaramillo, coordinador, Grupo de Asuntos ante la CIJ, Ministerio de Relaciones Exteriores, 
Sr. Giovanny Andrés Vega Barbosa, Grupo de Asuntos ante la CIJ, Ministerio de Relaciones Exteriores,

Sra. Ana María Durán López, Grupo de Asuntos ante la CIJ, Ministerio de Relaciones Exteriores,

Sr. Camilo Alberto Gómez Niño, Grupo de Asuntos ante la CIJ, Ministerio de Relaciones Exteriores,

Sr. Juan David Veloza Chará, Tercer Secretario, Grupo de Asuntos ante la CIJ, Ministerio de Relaciones Exteriores,

como asesores jurídicos;

Almirante Luis Hernán Espejo, Armada Nacional de Colombia,

Capitán de navío William Pedroza, Oficina de Asuntos Internacionales, Armada Nacional de Colombia,

Capitán de fragata Hermann León, Dirección Marítima (DIMAR), Armada Nacional de Colombia,

Sr. Scott Edmonds, cartógrafo, International Mapping,

Sr. Thomas Frogh, cartógrafo, International Mapping,

como consejeros técnicos;

Sra. Charis Tan, abogada y litigante, Singapur, miembro de la Barra de Nueva York, litigante, Inglaterra y Gales, Eversheds LLP, Singapur,

Sr. Eran Sthoeger, LLM, New York University School of Law,

Sr. Renato Raymundo Treves, asociado, Curtis, Mallet-Prevost, Colt \& Mosle LLP, Milán,

Sr. Lorenzo Palestini, candidato a PhD, graduate Institute of International and Development Studies, Ginebra,

como asistentes jurídicos,

La Corte, compuesta según se indicó arriba, tras deliberar

profiere la siguiente sentencia:

1. El 16 de septiembre de 2013, el gobierno de la República de Nicaragua (de ahora en adelante 'Nicaragua') presentó ante la Secretaría de la Corte una demanda introductiva de instancia contra la República de 
Colombia (de ahora en adelante 'Colombia') con relación a una "controversia [que se] refiere a la delimitación de las fronteras entre, por un lado, la plataforma continental de Nicaragua más allá del límite de 200 millas náuticas desde las líneas de base desde las que se mide la anchura del mar territorial de Nicaragua y, por otra parte, la plataforma continental de Colombia".

En su demanda, Nicaragua busca basar la jurisdicción de la Corte en el artículo XXXI del Tratado Americano de Soluciones Pacíficas firmado el 30 de abril de 1948, designado oficialmente, según su artículo LX, como el 'Pacto de Bogotá' (de ahora en adelante referido como 'Pacto de Bogotá').

Adicionalmente, Nicaragua afirma que el objeto-materia de su demanda continúa estando dentro de la jurisdicción de la Corte establecida en el asunto relativo al Diferendo territorial y marítimo (Nicaragua c. Colombia). En particular, sostiene que la Corte, en su sentencia del 19 de noviembre de 2012 (de ahora en adelante 'la decisión de 2012'), no determinó definitivamente la cuestión relativa a la delimitación de la plataforma continental entre Nicaragua y Colombia en el área más allá de las 200 millas náuticas desde la costa nicaragüense, "tal cuestión estuvo y aún se encuentra ante la Corte".

2. De conformidad con el artículo 40, párrafo 2, del Estatuto de la Corte, el Secretario comunicó inmediatamente la demanda al gobierno de Colombia; y, de acuerdo con el párrafo 3 de ese artículo, los demás Estados admitidos para comparecer ante la Corte fueron notificados de la demanda.

3. Como la Corte no cuenta con ningún juez de la nacionalidad de las partes, cada una hizo uso del derecho que le confiere el artículo 31, párrafo 3, del Estatuto para designar un juez ad hoc para el presente caso. Nicaragua seleccionó al Sr. Leonid Skotnikov y Colombia, al Sr. Charles N. Brower.

4. Mediante providencia del 9 de diciembre de 2013, la Corte estableció el 9 de diciembre de 2014 como la fecha de expiración del plazo para la presentación de la memoria de Nicaragua y el 9 de diciembre de 2015 para la presentación de la contramemoria de Colombia.

5. El 14 de agosto de 2014, antes de la expiración del plazo para la presentación de la memoria de Nicaragua, Colombia, basándose en el artículo 79 del Reglamento de la Corte, presentó excepciones preliminares a la jurisdicción de la Corte y a la admisibilidad de la demanda. Por su parte, Nicaragua, mediante carta del 16 de septiembre de 2014, a pesar de expresar su sorpresa de que dichas excepciones fueran presentadas cuatro meses antes del vencimiento del plazo para la presentación de su 
memoria, solicitó a la Corte, en el caso en que el procedimiento sobre el fondo del asunto se suspendiera, otorgarle un período de tiempo suficiente para presentar una declaración escrita de sus observaciones y pretensiones respecto de esas excepciones.

Por consiguiente, mediante providencia del 19 de septiembre de 2014, la Corte, anotando que, en virtud del artículo 79, párrafo 5, de su Reglamento, el procedimiento sobre el fondo del asunto quedaba suspendido, fijó el 19 de enero de 2015 como la fecha de expiración del plazo para la presentación por parte de Nicaragua de una declaración escrita de sus observaciones y pretensiones respecto de las excepciones preliminares presentadas por Colombia. Nicaragua presentó dicha declaración dentro del plazo establecido. El caso quedó así listo para audiencias públicas respecto de las excepciones preliminares.

6. De acuerdo con las instrucciones de la Corte en virtud del artículo 43 del Reglamento de la Corte, el Secretario notificó a los Estados partes del Pacto de Bogotá según lo señalado en el párrafo 1 del artículo 63 del Estatuto de la Corte. Conforme con las disposiciones del artículo 69, párrafo 3, del Reglamento de la Corte, el Secretario, mediante carta del 10 de noviembre de 2014, también envió a la Organización de los Estados Americanos (de ahora en adelante 'OEA') la notificación prevista por el artículo 34, párrafo 3, del Estatuto de la Corte, explicando que las copias de las excepciones preliminares presentadas por Colombia y la declaración escrita que sería presentada por Nicaragua se comunicarían oportunamente. Mediante carta del 5 de enero de 2015, y antes de recibir copias de estos escritos, el Secretario General de la OEA señaló que la organización no tenía intención de presentar observaciones escritas en el sentido del artículo 69, párrafo 3, del Reglamento de la Corte. Mediante carta del 30 de enero de 2015, el Secretario, tomando nota del hecho de que la OEA no tenía intención de presentar observación alguna, y teniendo en cuenta la confidencialidad de los documentos, aconsejó al Secretario General de la OEA que, a menos de que hubiese una razón específica de por qué la organización deseaba recibir copia del procedimiento escrito, no se le proporcionaría copia alguna.

7. Refiriéndose al artículo 53, párrafo 1, del Reglamento de la Corte, el gobierno de la República de Chile solicitó que se le proporcionaran copias de los escritos y copias anexadas en el caso. Después de haber consultado a las partes, de conformidad con esa misma disposición, el Presidente de la Corte decidió acceder a esa solicitud. El Secretario comunicó debidamente esa decisión al gobierno de Chile y a las partes. 
8. De conformidad con el artículo 53, párrafo 2, del Reglamento de la Corte, la Corte, tras haber consultado a las partes, decidió que las copias de las excepciones preliminares de Colombia y las observaciones escritas de Nicaragua serían de acceso público al momento de dar inicio al procedimiento oral.

9. Las audiencias públicas relativas a las excepciones preliminares de Colombia se llevaron a cabo del lunes 5 de octubre de 2015 al viernes 9 de octubre de 2015, en las cuales la Corte escuchó los argumentos y respuestas de:

$\begin{array}{ll}\text { Por Colombia } & \text { S. E. Sr. Manuel José Cepeda Espinosa, } \\ & \text { Sir Michael Wood, } \\ & \text { Sr. Mathias Herdegen, } \\ & \text { Sr. Rodman R. Bundy, } \\ & \text { Sr. W. Michael Reisman, } \\ & \text { Sr. Tulio Treves, } \\ & \text { S. E. Sr. Carlos Gustavo Arrieta Padilla. } \\ \text { Por Nicaragua } & \text { S. E. Sr. Carlos José Argüello Gómez, } \\ & \text { Sr. Antonio Remiro Brotóns, } \\ & \text { Sr. Alain Pellet, } \\ & \text { Sr. Alex Oude Elferink, } \\ & \text { Sr. Vaughan Lowe. }\end{array}$ St. Modhan R. Bundy, Sr. Rodman R. Bundy, Sr. W. Michael Reisman, Sr. Tulio Treves, S. E. Sr. Carlos Gustavo Arrieta Padilla.

S. E. Sr. Manuel josé Cepeda Espinosa,
S. E. Sr. Carlos José Argüello Gómez, Sr. Antonio Remiro Brotóns, Oetlet, Sr. Vaughan Lowe.

10. En su demanda, las siguientes pretensiones fueron presentadas por Nicaragua:

\begin{abstract}
"Nicaragua le solicita a la Corte que juzgue y declare:
Primero: El curso preciso de la frontera marítima entre Nicaragua y Colombia en las áreas de la plataforma continental que pertenecen a cada uno más allá de las fronteras establecidas por la Corte en la decisión del 19 de noviembre de 2012.

Segundo: Los principios y reglas de derecho internacional que determinan los derechos y deberes de los dos Estados en relación con el área donde se superponen los reclamos de plataforma continental y el uso de sus recursos, a la espera de la delimitación de la frontera marítima entre ellos más allá de las 200 millas náuticas desde la costa de Nicaragua".
\end{abstract}


11. En las piezas escritas, las siguientes pretensiones fueron presentadas en nombre de las partes:

En nombre del gobierno de Colombia,

en las excepciones preliminares:

"La República de Colombia solicita a la Corte que juzgue y declare, por las razones expuestas en este alegato:

1. que carece de jurisdicción respecto del proceso iniciado por Nicaragua en su demanda del 16 de septiembre de 2013; o, en subsidio,

2. que las pretensiones presentadas contra Colombia en la demanda del 16 de septiembre de 2013 son inadmisibles".

\section{En nombre del gobierno de Nicaragua,}

en la declaración escrita de sus observaciones y pretensiones respecto de las excepciones preliminares presentadas por Colombia:

"Por las razones anteriores, la República de Nicaragua solicita a la Corte juzgar y declarar que las excepciones preliminares presentadas por la República de Colombia, respecto tanto de la jurisdicción de la Corte como de la admisibilidad del caso, deben ser rechazadas".

12. En el procedimiento oral respecto de las excepciones preliminares, las siguientes pretensiones fueron presentadas por las partes:

\section{En nombre del gobierno de Colombia,}

en la audiencia del 7 de octubre de 2015:

"Por las razones expuestas en [sus] alegatos escritos y orales respecto de las excepciones preliminares, la República de Colombia solicita a la Corte juzgar y declarar:

1. que carece de jurisdicción respecto del proceso iniciado por Nicaragua en su demanda del 16 de septiembre de 2013; o, en subsidio, 
2. que las pretensiones presentadas contra Colombia en la demanda del 16 de septiembre de 2013 son inadmisibles".

En nombre del gobierno de Nicaragua,

en la audiencia del 9 de octubre de 2015:

"En vista de las razones que Nicaragua ha presentado en sus observaciones escritas y durante las audiencias, la República de Nicaragua solicita a la Corte:

- rechazar las excepciones preliminares de la República de Colombia; y

- proceder con el análisis del fondo del asunto".

\section{Introducción}

13. Cabe recordar que, en este proceso, Nicaragua busca fundamentar la jurisdicción de la Corte en el artículo XXXI del Pacto de Bogotá. Según esta disposición, los Estados partes del Pacto reconocen la jurisdicción de la Corte como obligatoria en "todas las controversias de naturaleza jurídica” (ver parágrafo 19 infra).

14. Adicionalmente, Nicaragua sostiene que el objeto-materia de su demanda continúa estando dentro de la jurisdicción de la Corte, tal y como esta fue establecida en el asunto relativo al Diferendo territorial y maritimo (Nicaragua c. Colombia), porque en la decisión de 2012 (ICJ Reports 2012 (II), p. 624), la Corte no se pronunció definitivamente sobre la cuestión - que le fue sometida - de la delimitación de la plataforma continental entre Nicaragua y Colombia en el área más allá de las 200 millas náuticas desde la costa nicaragüense.

15. Colombia ha presentado cinco excepciones preliminares a la jurisdicción de la Corte o a la admisibilidad de la demanda de Nicaragua. Según la primera excepción preliminar presentada por Colombia, la Corte carece de jurisdicción ratione temporis bajo el Pacto de Bogotá porque el procedimiento fue iniciado por Nicaragua el 16 de septiembre de 2013, después de que la transmisión del aviso de la denuncia del Pacto por parte de Colombia se hiciera efectiva el 27 de noviembre de 2012. En su segunda 
excepción, Colombia argumenta que la Corte no posee una "jurisdicción continua" porque abordó completamente la pretensión de Nicaragua en el Diferendo territorial y marítimo respecto a la delimitación de la plataforma continental entre Nicaragua y Colombia en el área más allá de las 200 millas náuticas de la costa nicaragüense. Colombia afirma en su tercera excepción que las cuestiones presentadas por Nicaragua en su demanda del 16 de septiembre de 2013 fueron "decididas explícitamente" por la Corte en la decisión de 2012; por lo tanto, la Corte carece de jurisdicción porque la pretensión de Nicaragua está prohibida por el principio res judicata. En su cuarta excepción, Colombia sostiene que la demanda de Nicaragua es un intento por apelar y revisar la decisión de 2012 de la Corte, y, como tal, la Corte no tiene jurisdicción para conocer de la demanda. Finalmente, de acuerdo con la quinta excepción de Colombia, la primera pretensión (respecto de la delimitación de la plataforma continental entre las partes en el área más allá de las 200 millas náuticas desde las líneas de base de Nicaragua) y la segunda pretensión (respecto de la determinación de los principios y reglas de derecho internacional que establecen los derechos y deberes de los dos Estados en el área relevante, a la espera de la delimitación) de Nicaragua en su demanda (ver parágrafo 10 supra) son inadmisibles. La primera pretensión es, a criterio de Colombia, inadmisible porque la Comisión de Límites de la Plataforma Continental (de ahora en adelante la 'CLPC') no ha realizado la recomendación a Nicaragua respecto de si, y de ser así en qué distancia, la plataforma continental exterior pretendida por Nicaragua se extiende más allá de las 200 millas náuticas. Según Colombia, la segunda pretensión es inadmisible porque, si "la Corte decide que carece de jurisdicción respecto de la primera pretensión o que esta es inadmisible, no se encontraría pendiente una cuestión ante la Corte". Colombia agrega que no habría un lapso respecto del cual aplicar una decisión respecto de la segunda pretensión, puesto que la Corte analizaría ambas pretensiones simultáneamente; por consiguiente, la segunda pretensión también resulta inadmisible porque, aun cuando la Corte pudiese conocer de ella, la decisión de la Corte carecería de objeto.

16. En sus observaciones escritas y pretensiones finales durante el procedimiento oral, Nicaragua solicita a la Corte rechazar íntegramente las excepciones preliminares presentadas por Colombia (ver parágrafos 11 у 12 supra).

17. En cuanto la segunda excepción preliminar de Colombia se refiere exclusivamente a la fuente de jurisdicción adicional sugerida por Nicaragua, la Corte abordará esta después de haber considerado las excepciones 
primera, tercera y cuarta. La quinta excepción preliminar, que se refiere a la admisibilidad de las pretensiones de Nicaragua, será analizada al final.

\section{Primera excepción preliminar}

18. La primera excepción preliminar de Colombia se fundamenta en que el artículo XXXI del Pacto de Bogotá no constituye una base de jurisdicción para la Corte, en la medida en que Colombia transmitió su aviso de denuncia del Pacto antes de que Nicaragua presentara su demanda en el presente asunto. Según Colombia, la notificación tiene efecto inmediato sobre la jurisdicción de la Corte bajo el artículo XXXI, con la consecuencia de que la Corte carece de jurisdicción respecto de cualquier procedimiento iniciado con posterioridad a la transmisión del aviso.

19. El artículo XXXI del Pacto de Bogotá establece:

"De conformidad con el inciso 2 del artículo 36 del Estatuto de la Corte Internacional de Justicia, las altas partes contratantes declaran que reconocen respecto a cualquier otro Estado americano como obligatoria ipso facto, sin necesidad de ningún convenio especial mientras esté vigente el presente tratado, la jurisdicción de la expresada Corte en todas las controversias de orden jurídico que surjan entre ellas y que versen sobre:

a) [1]a interpretación de un tratado;

b) [c]ualquier cuestión de derecho internacional;

c) [1] a existencia de todo hecho que, si fuere probado, constituiría la violación de una obligación internacional;

d) [1] a naturaleza o extensión de la reparación que ha de hacerse por el quebrantamiento de una obligación internacional".

20. La denuncia del Pacto de Bogotá es regulada por el artículo LVI, el cual indica:

"El presente tratado regirá indefinidamente, pero podrá ser denunciado mediante aviso anticipado de un año, transcurrido el cual cesará en sus efectos para el denunciante, quedando subsistente para los demás signatarios. La denuncia será dirigida a la Unión Panamericana, que la transmitirá a las otras partes contratantes. 
La denuncia no tendrá efecto alguno sobre los procedimientos pendientes iniciados antes de transmitido el aviso respectivo".

21. El 27 de noviembre de 2012, Colombia dio aviso de denuncia mediante una nota diplomática de la Ministra de Relaciones Exteriores al Secretario General de la OEA como cabeza de la Secretaría General de la OEA (sucesor de la Unión Panamericana). Este aviso señalaba que la denuncia de Colombia "rige a partir del día de hoy respecto de los procedimientos que se inicien después del presente aviso, de conformidad con el segundo párrafo del artículo LVI".

22. La demanda en el presente asunto fue presentada a la Corte tras la transmisión del aviso de denuncia por parte de Colombia, pero antes que el período de un año establecido en el primer párrafo del artículo LVI expirara.

23. Colombia sostiene que el artículo LVI del Pacto de Bogotá debe interpretarse de conformidad con las normas consuetudinarias de interpretación de tratados contenidas en los artículos 31 a 33 de la Convención de Viena sobre el Derecho de los Tratados de 1969 (de ahora en adelante la 'Convención de Viena'). Colombia se basa, en particular, en la regla general de interpretación del artículo 31 de la Convención de Viena, la cual requiere que "[u]n tratado deberá interpretarse de buena fe conforme el sentido corriente de que haya de atribuirse a los términos del tratado en el contexto de éstos y teniendo en cuenta su objeto y fin". Según Colombia, la aplicación de la regla general de interpretación lleva a la conclusión de que los procesos iniciados tras la transmisión del aviso de una denuncia se encuentran afectados por la denuncia.

24. Colombia afirma que la consecuencia natural de lo dispuesto expresamente en el segundo párrafo del artículo LVI del Pacto, de que la denuncia no tendrá efecto alguno sobre los procedimientos pendientes iniciados antes de la transmisión de un aviso, es que la denuncia resulta efectiva respecto de los procedimientos iniciados después de ese momento. Tal efecto se sigue, según Colombia, de la aplicación al segundo párrafo del artículo LVI de una interpretación a contrario como la aplicada por la Corte en su decisión del 16 de abril de 2013 en el asunto relativo a la Controversia fronteriza (Burkina Faso/Niger) (ICJ Reports 2013, pp. 83-84). Más aún, el adoptar una interpretación distinta negaría el effet utile al segundo párrafo 
y sería, por lo tanto, contrario al principio según el cual debe darse efecto a todas las palabras en un tratado. Colombia rechaza la sugerencia de que su interpretación del segundo párrafo del artículo LVI negaría el effet utile al primer párrafo de esta disposición. A pesar de que Colombia acepta que su interpretación implicaría que ninguno de los procedimientos establecidos en los capítulos 2 a 5 del Pacto pueden ser iniciados por, o en contra, de un Estado que ha transmitido del aviso de denuncia durante el año que el tratado permanece en vigor de conformidad con el primer párrafo del artículo LVI, sostiene que obligaciones sustantivas importantes contenidas en otros capítulos del Pacto permanecerían en vigor durante el período de un año, así el primer párrafo del artículo LVI tendría un efecto claro.

25. Colombia argumenta que su interpretación del artículo LVI la confirma el hecho de que, si los Estados partes del Pacto hubiesen querido establecer que la denuncia no afectaría ningún procedimiento iniciado durante el período de aviso de un año, podrían haber dicho esto fácilmente de manera expresa, concretamente adoptando una redacción similar a disposiciones en otros tratados, como el artículo 58, párrafo 2, del Convenio Europeo de Derechos Humanos de 1950, o del artículo 40, párrafo 2, de la Convención Europea sobre Inmunidad del Estado de 1972. Colombia también observa que la función y lenguaje del artículo XXXI son bastante similares a aquellos del artículo 36, párrafo 2, del Estatuto de la Corte y que los Estados generalmente reservan su derecho de retirar sus declaraciones bajo el artículo 36, párrafo 2 , sin aviso previo.

26. Finalmente, Colombia sostiene que su interpretación "también es consistente con la practica estatal de los Estados partes del Pacto" y los travaux préparatoires. Respecto del primer argumento, señala la falta de reacción, incluyendo la de Nicaragua, a la notificación del aviso de denuncia de Colombia, a pesar de la claridad de la declaración allí contenida de que la denuncia tendría efecto a partir de la fecha de la notificación "respecto de los procedimientos [...] [que] inicien después del presente aviso". También hace énfasis en que no hubo reacción de otros Estados partes del Pacto cuando El Salvador dio aviso de su denuncia en 1973, a pesar de que el aviso de la denuncia indicaba "tendría efecto a partir de hoy". En cuanto a los travaux préparatoires, Colombia afirma que el primer párrafo del artículo LVI fue tomado del artículo $9^{\circ}$ del Tratado General de Arbitraje Interamericano de 1929 (y la disposición paralela en el artículo 16 de la Convención General de Conciliación Interamericana de 1929). Colombia sostiene que lo que se convirtió en el segundo párrafo del artículo LVI fue adicionado como resultado de una iniciativa de Estados Unidos de América 
en 1938 y que fue aceptada por el Comité Jurídico Interamericano en 1947 e incorporada en el texto firmado en 1948. Según Colombia, esta historia muestra que los Estados partes del Pacto de Bogotá buscaron incorporar una disposición que limitara el efecto del primer párrafo del artículo LVI.

27. Nicaragua afirma que la jurisdicción de la Corte se determina por el artículo XXXI del Pacto de Bogotá, con el que Colombia y Nicaragua han reconocido la jurisdicción de la Corte "mientras esté vigente el presente tratado". El tiempo por el que el tratado se encuentre en vigor lo determina el primer párrafo del artículo LVI, que establece que el Pacto estará en vigor, para un Estado que haya dado aviso de la denuncia, por el término de un año a partir de la fecha de esa notificación. Como el día en que la jurisdicción de la Corte debe establecerse es aquel en el que la demanda se presenta, y como la demanda de Nicaragua fue presentada durante el lapso de un año después de que Colombia dio su aviso de denuncia del Pacto, se sigue — según Nicaragua — que la Corte tiene jurisdicción en el presente asunto. Nicaragua sostiene que nada en el segundo párrafo del artículo LVI es contrario a esa conclusión y ninguna inferencia puede derivar del silencio de ese párrafo respecto de los procedimientos iniciados entre la notificación del aviso de la denuncia y el día en que el tratado cesa en sus efectos para el Estado denunciante; en cualquier evento, dicha inferencia no puede prevalecer respecto del lenguaje expreso del artículo XXXI y el primer párrafo del artículo LVI.

28. Esta conclusión la refuerza, en opinión de Nicaragua, el objeto y fin del Pacto. Nicaragua recuerda que, según la Corte "[e]s [...] suficientemente claro a partir del Pacto que el propósito de los Estados americanos al redactarlo era fortalecer sus compromisos mutuos respecto del arreglo judicial" - Acciones armadas fronterizas y transfronterizas (Nicaragua c. Honduras), Jurisdicción y admisibilidad, fallo, ICJ Reports 1988, p. 89, para. 46- La interpretación de Colombia del segundo párrafo del artículo LVI conduciría, sostiene Nicaragua, a dejar desprovisto de todo significado lo establecido expresamente por el artículo XXXI de que los Estados partes del Pacto aceptan la jurisdicción de la Corte mientras el Pacto esté vigente entre ellos, así como lo establecido expresamente por el artículo LVI de que el Pacto se mantendrá vigente por un año después de la notificación del aviso de denuncia. Según Nicaragua, esto también haría imposible el 
propósito del Pacto — como ha sido definido por la Corte- durante el lapso de un año desde el aviso de la denuncia.

29. Nicaragua no acepta el argumento de Colombia de que su interpretación del segundo párrafo del artículo LVI dejaría aún obligaciones importantes en firme durante el período de aviso de un año. Según Nicaragua, la interpretación de Colombia extraería del efecto del primer párrafo del artículo LVI todos los procedimientos de buenos oficios y mediación (capítulo 2 del Pacto), investigación y conciliación (capítulo 3), procedimiento judicial (capítulo 4) y arbitraje (capítulo 5), los cuales en su conjunto comprenden 41 de los 60 artículos del Pacto. De las disposiciones restantes, varias - como el artículo LII sobre ratificación y el artículo LIV sobre la adhesión al Pacto- son disposiciones que han cumplido su propósito y no cumplirían función alguna durante el período de aviso de un año, mientras otras — como los artículos III al VI— están inexorablemente ligadas a los procedimientos de los capítulos 2 a 5 y no imponen obligación alguna independiente de los procedimientos. La interpretación de Colombia del artículo LVI dejaría entonces únicamente 6 artículos de los 60 del Pacto con alguna función durante el período de aviso de un año prescrito por el primer párrafo del artículo LVI. Nicaragua también anota que el título del capítulo 1 de este Pacto es "Obligación general de resolver las controversias por medios pacíficos" y afirma que sería extraño interpretar el artículo LVI del Pacto como si este mantuviera este capítulo en vigor entre un Estado que ha dado aviso de denuncia y las demás partes del Pacto, mas no los capítulos que contienen los procedimientos a los que el capítulo se refiere.

30. Finalmente, Nicaragua niega que la práctica de los Estados partes del Pacto o los travaux préparatoires respalden la interpretación de Colombia. Hasta el momento en cuanto a la práctica se refiere, Nicaragua mantiene que nada puede concluirse de la ausencia de respuesta a los avisos de denuncia de El Salvador y Colombia, pues no existía obligación para los otros Estados partes del Pacto de responder. En cuanto a los travaux préparatoires, ellos no sugieren razón alguna de por qué lo que llegó a ser el segundo párrafo del artículo LVI fue incluido o lo que este pretendía significar. Lo más importante, los travaux préparatoires no contienen algo que sugiera que los Estados partes del Pacto pretendían, al adicionar lo que se convirtió en el segundo párrafo, restringir el alcance del primer párrafo del artículo LVI. En consideración de Nicaragua, el segundo párrafo del artículo LVI, a pesar de no ser necesario, sirve a un propósito bastante útil al hacer claro que la denuncia no afecta los procedimientos pendientes. 
31. La Corte recuerda que la fecha en que su jurisdicción debe establecerse es el día en que la demanda es presentada en la Corte - Aplicación de la Convención para Prevenir y Sancionar el Delito de Genocidio (Croacia c. Serbia), Excepciones preliminares, fallo, ICJ Reports 2008, pp. 437-438, paras. 79-80; Aplicación de la Convención para Preveniry Sancionar el Delito de Genocidio (Bosnia \& Herzegovina c. Yugoslavia), Excepciones preliminares, fallo, ICJ Reports 1996 (II), p. 613, para. 26-. Una consecuencia de esta regla es que "la remoción, después de que la demanda se ha presentado, de un elemento sobre el que la jurisdicción de la Corte depende no tiene y no puede tener un efecto retroactivo" - Aplicación de la Convención para Preveniry Sancionar el Delito de Genocidio (Croacia c. Serbia), Excepciones preliminares, fallo, ICJ Reports 2008 , p. 438 , para. 80). Por lo tanto, aun cuando la disposición del tratado con la que se confiere jurisdicción a la Corte deja de estar en vigor entre el demandante y el demandado, o cualquiera de las declaraciones de una parte bajo el artículo 26, párrafo 2, del Estatuto de la Corte expira o es retirada, después de que la demanda se ha presentado, ese hecho no impide a la Corte tener jurisdicción. Como la Corte sostuvo en el asunto Nottebohm:

"Cuando la demanda es presentada en un momento donde el derecho aplicable entre las partes implica la jurisdicción obligatoria de la Corte [...] la presentación de la demanda es simplemente un condición necesaria para permitir a la cláusula de jurisdicción obligatoria producir sus efectos respecto de la pretensión presentada en la demanda. Una vez esta condición se ha visto satisfecha, la Corte debe examinar la pretensión; tiene jurisdicción para tratar todos sus aspectos, sin importar si estos se relacionan a la jurisdicción, admisibilidad o el fondo. Un hecho extrínseco como la posterior caducidad de la declaración, en razón del vencimiento de su periodo o su denuncia, no puede privar a la Corte de la jurisdicción que ya se ha establecido". —Nottebohm (Liechtenstein c. Guatemala), Excepciones preliminares, fallo, ICJ Reports 1953, p. 123-.

32. En virtud del artículo XXXI, los Estados partes al Pacto de Bogotá reconocen como obligatoria la jurisdicción de la Corte, "mientras esté vigente el presente tratado". El primer párrafo del artículo LVI establece que, tras la denuncia del Pacto por un Estado parte, el Pacto permanecerá vigente entre el Estado denunciante y los otros Estados partes por un período de un año siguiente al aviso de la denuncia. No se disputa que, 
si estas disposiciones se analizaran por separado, ellas serían suficientes para conferir jurisdicción en el presente asunto. El Pacto se encontraba en vigor entre Colombia y Nicaragua el día que la demanda fue presentada y, de conformidad con la regla establecida en el párrafo 31 supra, el hecho de que el Pacto dejara posteriormente de estar en vigor entre ellos no afecta esa jurisdicción. La única pregunta presentada por la primera excepción preliminar de Colombia, por lo tanto, es si el segundo párrafo del artículo LVI altera el que sería de otra manera el efecto del primer párrafo y, por ende, llevaría a la conclusión de que la Corte carece de jurisdicción respecto del presente asunto, a pesar de que este fue iniciado mientras el Pacto se encontraba aún en vigor entre Nicaragua y Colombia.

33. Esta cuestión debe ser resuelta mediante la aplicación a las disposiciones relevantes del Pacto de Bogotá de las reglas sobre interpretación de tratados contenidas en los artículos 31 a 33 de la Convención de Viena. A pesar de que esta Convención no está en vigor entre las partes y no es, en cualquier caso, aplicable a tratados concluidos antes de que esta entrara en vigor, como el Pacto de Bogotá, está bien establecido que los artículos 31 a 33 de la Convención de Viena reflejan reglas de derecho internacional consuetudinario - Avena y otros nacionales mexicanos (México c. Estados Unidos de América), fallo, ICJ Reports 2004 (I), p. 48, para. 83; La Grand (Alemania c. Estados Unidos de América), fallo, ICJ Reports 2001, p. 502, para. 101; Plataformas petroliferas (República Islámica de Irán c. Estados Unidos de América), Excepciones preliminares, fallo, ICJ Reports 1996 (II), p. 812, para. 23; Controversia territorial (Yamabiriya Árabe Lybia/ Chad), fallo, ICJ Reports 1994, p. 21, para. 41; laudo arbitral del 31 de julio de 1989 (Guinea-Bisán c. Senegal), fallo, ICJ Reports 1991, p. 70, para. 48-. Las partes están de acuerdo en que estas normas son aplicables. El artículo 31, que establece la regla general de interpretación, requiere que "[u]n tratado deberá interpretarse de buena fe conforme el sentido corriente de que haya de atribuirse a los términos del tratado en el contexto de éstos y teniendo en cuenta su objeto y fin".

34. El argumento de Colombia respecto de la interpretación del segundo párrafo del artículo LVI no se basa en el sentido corriente de los términos usados en esa disposición, sino en una inferencia que puede extraerse de lo que ese párrafo no establece. Ese párrafo no dice algo respecto de los procedimientos iniciados tras la notificación del aviso de la denuncia y antes de que expire el período de un año a que hace referencia el primer párrafo del artículo LVI. Colombia solicita a la Corte extraer del silencio de esta disposición que ella carece de jurisdicción respecto del procedimiento iniciado después de que se dio el aviso de la denuncia. 
Según Colombia, esa inferencia debe extraerse a pesar que el Pacto permanezca en vigor para el Estado denunciante, porque el período de aviso de un año estipulado por el primer párrafo del artículo LVI no ha concluido. La inferencia se dice que sigue de una lectura a contrario de la disposición.

35. Una lectura a contrario de la disposición de un tratado - por la cual el hecho de que la disposición establece expresamente un tipo de situación permite justificar la inferencia de que otras situaciones comparables están excluidas - ha sido usada tanto por la presente Corte — ver, $e$. g., Diferendo territorial y marítimo (Nicaragua c. Colombia), Solicitud de Honduras de permiso para intervenir, fallo, ICJ Reports 2011 (II), p. 432, para. 29- como por la Corte Permanente de Justicia Internacional (S. S. 'Wimbledon', fallo, 1923, PCIJ Serie $A N^{\circ} 1$, pp. 23-24). Sin embargo, esta interpretación solo se permite cuando es apropiada a la luz del texto de todas las disposiciones bajo análisis, su contexto y el objeto y fin del tratado. Más aún, incluso cuando una interpretación a contrario se justifica, es importante determinar precisamente la inferencia que su aplicación requiere en cualquier caso.

36. El segundo párrafo del artículo LVI establece que "la denuncia no tendrá efecto alguno sobre los procedimientos pendientes iniciados antes de transmitido el aviso respectivo". No obstante, no es la denuncia per se la que es capaz de tener efecto sobre la jurisdicción de la Corte según el artículo XXXI del Pacto, sino la terminación del tratado (entre el Estado denunciante y los otros Estados partes) que resulta de la denuncia. Esto se sigue de los términos del artículo XXXI, el cual establece que los Estados partes del Pacto reconocen la jurisdicción de la Corte como obligatoria inter se "mientras esté vigente el presente tratado", y del sentido corriente de las palabras usadas en el artículo LVI. El primer párrafo del artículo LVI establece que el tratado puede terminar mediante denuncia, pero esa terminación ocurre únicamente después del período de un año desde el aviso de la denuncia. Es, por lo tanto, el primer párrafo el que determina los efectos de la denuncia. El segundo párrafo del artículo LVI confirma que los procedimientos iniciados antes de la transmisión del aviso de la denuncia pueden continuar sin importar la denuncia y así su continuidad se asegura sin importar lo establecido por el primer párrafo sobre los efectos de la denuncia en su conjunto.

37. El argumento de Colombia es que, si uno aplica una interpretación a contrario al segundo párrafo del artículo LVI, se sigue del enunciado "la denuncia no tendrá efecto alguno sobre los procedimientos pendientes iniciados antes de transmitido el aviso respectivo [de la denuncia]" que la denuncia tiene un efecto respecto de los procedimientos iniciados des- 
pués de la transmisión del aviso. Colombia sostiene que el efecto es que cualquier procedimiento iniciado después de esta fecha se encuentra en su totalidad por fuera del tratado. En el caso de los procedimientos iniciados después de esa fecha, Colombia sostiene que estos, por lo tanto, se encuentran por fuera de la jurisdicción que confiere el artículo XXXI. Sin embargo, esta interpretación es contraria el lenguaje del artículo XXXI, el cual establece que los Estados partes del Pacto reconocen la jurisdicción de la Corte como obligatoria "mientras esté vigente el presente tratado".

El segundo párrafo del artículo LVI está abierto a una interpretación diferente, la cual es compatible con el lenguaje del artículo XXXI. Según esta interpretación, mientras los procedimientos iniciados antes de la transmisión del aviso de la denuncia pueden continuar en cualquier caso y no se encuentran por tanto sujetos al primer párrafo del artículo LVI, el efecto de la denuncia sobre procedimientos iniciados después de esta fecha se rige por el primer párrafo. Como el primer párrafo establece que la denuncia pone fin al tratado para el Estado denunciante únicamente después de que el período de un año haya transcurrido, los procedimientos iniciados durante este año son iniciados mientras que el Pacto se encuentra en vigor. Ellos están, por lo tanto, dentro del ámbito de la jurisdicción del artículo XXXI.

38. Más aún, de conformidad con la regla de interpretación contenida en el artículo 31, párrafo 1, de la Convención de Viena, el texto del segundo párrafo del artículo LVI debe ser examinado en su contexto. Colombia admite (ver parágrafo 28 supra) que su lectura del segundo párrafo tiene el efecto, durante el período de un año que el primer párrafo del artículo LVI establece entre el aviso de la denuncia y la terminación del tratado para el Estado denunciante, de que ninguno de los procedimientos para la solución pacífica de controversias establecidos por los capítulos 2 a 5 del Pacto pueden ser invocados entre el Estado denunciante y cualquier otro Estado parte del Pacto. Según Colombia, únicamente las disposiciones de los otros capítulos del Pacto permanecerían en vigor entre el Estado denunciante y los otros Estados partes, durante el período de aviso de un año. No obstante, los capítulos 2 a 5 contienen todas las disposiciones del Pacto que tratan con los distintos procedimientos para la solución pacífica de controversias y, como la Corte explicará, juegan un papel fundamental en la estructura de las obligaciones establecidas por el Pacto. El resultado de la interpretación propuesta por Colombia del segundo párrafo del artículo LVI sería que, durante el año siguiente al aviso de la denuncia, la mayoría de artículos del Pacto, incluyendo sus disposiciones más importantes, no 
serían aplicables entre el Estado denunciante y los otros Estados partes. Un resultado tal es difícil de reconciliar con los términos expresos del primer párrafo del artículo LVI, el cual establece que "el presente tratado" estará en vigor durante el período de un año sin distinguir entre los distintos capítulos del Pacto, tal y como Colombia busca hacerlo.

39. También resulta necesario considerar si la interpretación de Colombia es consistente con el objeto y fin el Pacto de Bogotá. Ese objeto y fin lo sugiere el título completo del Pacto, a saber, Tratado Americano de Soluciones Pacíficas. El preámbulo indica que el Pacto fue adoptado en cumplimiento del artículo XXIII de la Carta de la OEA. El artículo XXIII (actualmente el artículo XXVII) expresa que:

“[u]n tratado especial establecerá los medios adecuados para resolver las controversias y determinará los procedimientos pertinentes a cada uno de los medios pacíficos, en forma de no dejar que controversia alguna entre los Estados americanos pueda quedar sin solución definitiva dentro de un plazo razonable".

Ese énfasis en establecer medios para la solución pacífica de controversias como el objeto y fin del Pacto es confirmado por las disposiciones del capítulo 1 del Pacto, el cual se titula "Obligación general de resolver las controversias por medios pacíficos". El artículo I establece:

"Las altas partes contratantes, reafirmando solemnemente sus compromisos contraídos por anteriores convenciones y declaraciones internacionales, así como por la Carta de las Naciones Unidas, convienen en abstenerse de la amenaza, del uso de la fuerza o de cualquier otro medio de coacción para el arreglo de sus controversias y en recurrir en todo tiempo a procedimientos pacíficos".

El artículo II establece:

"Las altas partes contratantes reconocen la obligación de resolver las controversias internacionales por los procedimientos pacíficos regionales antes de llevarlas al Consejo de Seguridad de las Naciones Unidas. En consecuencia, en caso de que entre dos o más Estados signatarios se suscite una controversia que, en opinión de las partes, no pueda ser resuelta por negociaciones directas a través de los medios diplomáticos usuales, las partes se comprometen a hacer uso de los procedimientos 
establecidos en este tratado en la forma y condiciones previstas en los artículos siguientes, o bien de los procedimientos especiales que, a su juicio, les permitan llegar a una solución”.

Finalmente, la Corte recuerda que, en su decisión de 1988 en el asunto de las Acciones armadas, citado en el parágrafo 28 supra, sostuvo que "el propósito de los Estados americanos al redactarlo [el Pacto] era fortalecer sus compromisos mutuos respecto del arreglo judicial" - Acciones armadas fronterizas y transfronterizas (Nicaragua c. Honduras), Jurisdicción y admisibilidad, fallo, ICJ Reports 1988, p. 89, para. 46-.

40. Estos factores dejan claro que el objeto y fin del Pacto es promover la solución pacífica de controversias por los procedimientos establecidos en el Pacto. Aunque Colombia argumenta que la referencia a "procedimientos... regionales" en el primer párrafo del artículo II no se limita a los procedimientos establecidos en el Pacto, el artículo II debe ser interpretado en su conjunto. Resulta claro del uso del término "en consecuencia” al inicio del segundo párrafo del artículo II que la obligación de recurrir a procedimientos regionales, los cuales las partes "reconocen" en el primer párrafo, debe dársele efecto mediante el uso de los procedimientos indicados en los capítulos 2 a 5 del Pacto. Colombia sostiene que su interpretación del segundo párrafo del artículo LVI dejaría al artículo II —el cual contiene una de las obligaciones centrales del Pacto- en vigor durante el período de un año. Sin embargo, la Corte observa que la interpretación de Colombia impediría tanto al Estado denunciante como, en la medida en que tengan una controversia con el Estado denunciante, a los demás Estados partes el acceso a los procedimientos designados para dar efecto a la obligación de hacer uso de procedimientos regionales. Como la Corte ya lo ha explicado (ver parágrafo 34 supra), esta interpretación se sigue no de los términos del segundo párrafo del artículo LVI, sino de una inferencia que, según Colombia, debe extraerse del silencio de ese párrafo respecto de procedimientos iniciados durante el período de un año. La Corte no encuentra base alguna para extraer de ese silencio una inferencia que no sería consistente con el objeto y fin del Pacto de Bogotá.

41. Una parte esencial del argumento de Colombia es que su interpretación resulta necesaria para dar effet utile al segundo párrafo del artículo LVI. Colombia sostiene que, si el segundo párrafo se limita a asegurar que los procedimientos iniciados antes de la fecha de transmisión del aviso de notificación pueden continuar después de esta fecha, esta disposición resultaría entonces superflua. La regla de que los hechos que ocurran 
tras la fecha en que la demanda fue presentada no priva a la Corte de la jurisdicción que existía en esa fecha (ver parágrafo 31 supra) aseguraría, en cualquier circunstancia, que la denuncia del Pacto no afectara procedimientos que han sido iniciados antes de la denuncia.

La Corte ha reconocido que, en general, la interpretación de un tratado debe buscar dar efecto a cada uno de los términos en ese tratado y ninguna disposición puede ser interpretada de manera que la deje desprovista de sentido o efecto - Aplicación de la Convención Internacional sobre la Eliminación de todas las Formas de Discriminación Racial (Georgia c. Federación Rusa), Excepciones preliminares, fallo, ICJ Reports 2011 (I), pp. 125-126, para. 133; Canal de Corfu (Reino Unido c. Albania), Fondo, fallo, ICJ Reports 1949, p. 24-. Sin embargo, existen ocasiones en que las partes de un tratado adoptan una disposición para evitar toda duda, aun cuando esa disposición no es estrictamente necesaria. Por ejemplo, el artículo LVIII del Pacto de Bogotá establece que algunos tratados interamericanos anteriores no cesarían en sus efectos respecto de los Estados partes del Pacto, tan pronto como el Pacto entrara en vigor. Así mismo, el artículo LIX establece que lo dispuesto en el artículo LVIII "no se aplicará a los procedimientos ya iniciados o pactados" de conformidad con alguno de esos tratados anteriores. Mientras que ninguna de las partes se refirió a estas disposiciones, si uno aplica la aproximación sugerida por Colombia respecto del artículo LVI, el artículo LIX debería ser considerado entonces innecesario. Parece que los Estados partes del Pacto de Bogotá consideraron que era deseable incluir el artículo LIX por precaución. El hecho de que los Estados partes del Pacto consideraran que incluir el artículo LIX tenía un propósito útil, a pesar de no ser estrictamente necesario, debilita el argumento de Colombia de que la disposición similar del artículo LVI no podía haber sido incluida por esa razón.

42. La Corte también considera que, al buscar el significado del segundo párrafo del artículo LVI, no debe adoptar una interpretación que deje al primer párrafo de ese artículo desprovisto de sentido o efecto. El primer párrafo establece que el Pacto estará en vigor por el período de un año siguiente a la transmisión del aviso de la denuncia. Sin embargo, la interpretación de Colombia limitaría el efecto de esta disposición a los capítulos 1, 6, 7 y 8 . El capítulo 8 contiene las disposiciones formales en cuestiones como la ratificación, entrada en vigor y registro, además de no imponer alguna obligación durante el período que sigue a la transmisión del aviso de denuncia. El capítulo 7 (titulado "Opiniones consultivas") contiene un solo artículo, que es meramente permisivo. El capítulo 6 también 
contiene una disposición, la cual únicamente requiere que, antes de que una parte recurra al Consejo de Seguridad respecto del incumplimiento de otra parte de las obligaciones que le imponga un fallo de la Corte o un laudo arbitral, debe promover una reunión de consulta de Ministros de Relaciones Exteriores.

El capítulo 1 ("Obligación general de resolver las controversias por medios pacíficos") contiene ocho artículos que imponen obligaciones importantes a los Estados partes, pero, como ya se ha mostrado (ver parágrafo 40 supra), el artículo II se refiere a la obligación de hacer uso de los procedimientos del Pacto (ninguno de los cuales estaría disponible durante el período de un año si la interpretación de Colombia se aceptara), mientras que los artículos III a VI no tienen efecto independiente de los procedimientos de los capítulos 2 a 5 . Esto deja únicamente tres artículos. El artículo I dispone que los Estados partes,

"reafirmando solemnemente sus compromisos contraídos por anteriores convenciones y declaraciones internacionales, así como por la Carta de las Naciones Unidas, convienen en abstenerse de la amenaza, del uso de la fuerza o de cualquier otro medio de coacción para el arreglo de sus controversias y en recurrir en todo tiempo a procedimientos pacíficos".

El artículo VII obliga a los Estados partes a no ejercer protección diplomática respecto de sus nacionales cuando esos nacionales hayan tenido los medios para acudir a los tribunales domésticos competentes. El artículo VIII establece que el recurso a medios pacíficos no impide el recurso a la legítima defensa en caso de un ataque armado.

La interpretación de Colombia del segundo párrafo del artículo LVI limitaría, por lo tanto, la aplicación del primer párrafo del artículo LVI a estos pocos artículos.

43. Colombia, basándose en el lenguaje usado en otros tratados, argumenta que, si los Estados partes del Pacto hubiesen querido establecer que los procedimientos iniciados en cualquier momento antes del vencimiento del plazo de un año estipulado por el primer párrafo del artículo LVI no se verían afectados, podrían fácilmente haber redactado una disposición en ese sentido. No obstante, y muy por el contrario, si los Estados partes del Pacto hubiesen intentado el resultado que Colombia afirma, podrían fácilmente haber redactado una disposición en ese sentido, pero decidieron no hacerlo. Por consiguiente, la comparación con los otros tratados no es un argumento persuasivo en favor de la interpretación de Colombia del 
segundo párrafo del artículo LVI. Tampoco es un argumento convincente el hecho de que varias declaraciones realizadas en virtud del artículo 36, párrafo 2, del Estatuto de la Corte, pueden darse por terminadas sin previo aviso. Tanto el artículo 36, párrafo 2, del Estatuto de la Corte como el artículo XXXI del Pacto de Bogotá establecen la jurisdicción obligatoria de la Corte. Sin embargo, el artículo 36, párrafo 2, del Estatuto, confiere jurisdicción únicamente respecto de aquellos Estados que también han presentado una declaración aceptando dicha jurisdicción. En su declaración del artículo 36, párrafo 2, un Estado es libre para indicar que la declaración puede ser retirada con efecto inmediato. Por el contrario, el artículo XXXI del Pacto de Bogotá es la obligación de un tratado, la cual no depende de una declaración unilateral para su implementación - Acciones armadas fronterizas y transfronterizas (Nicaragua c. Honduras), Jurisdicción y admisibilidad, fallo, ICJ Reports 1988, p. 84, para. 32-. Las condiciones bajo las que un Estado parte del Pacto puede dejar sin efecto su obligación se encuentran determinadas por las mismas disposiciones del Pacto. Por lo tanto, el hecho de que varios Estados hayan decidido redactar sus declaraciones en virtud del artículo 36, párrafo 2, de modo que puedan terminar su aceptación de la jurisdicción de la Corte con efecto inmediato, no da luces sobre la interpretación del Pacto.

44. La Corte ha señalado el argumento de Colombia (ver parágrafo 26 supra) respecto de la práctica estatal tras la denuncia del Pacto por El Salvador en 1973 y Colombia misma en 2012, con la cual Colombia hace referencia a la ausencia de reacción a los avisos de esas denuncias.

Ambos avisos de denuncia no fueron hechos en los mismos términos. Mientras el aviso de El Salvador indica que su denuncia "tendrá efecto a partir de hoy", no existe una referencia sobre el efecto que tendría inmediatamente tras la denuncia. Como el primer párrafo del artículo LVI requiere el aviso de un año para dar por terminado el tratado, cualquier aviso de denuncia tiene efectos de manera inmediata, en el sentido en que la transmisión del aviso tiene como efecto el inicio del período de un año. En consecuencia, ni el aviso de El Salvador, como tampoco la ausencia de cualquier comentario al respecto, pueden dar luces sobre la cuestión actualmente bajo análisis por la Corte.

El mismo aviso de denuncia de Colombia especifica que "[]a denuncia [del Pacto] rige a partir de hoy respecto de los procedimientos que se inicien después del presente aviso, de conformidad con el segundo párrafo del artículo LVI". Sin embargo, la Corte no puede extraer de la ausencia de una objeción por parte de los otros Estados partes del Pacto respecto 
de ese aviso la existencia de un acuerdo, en el sentido del artículo 31(3)(b) de la Convención de Viena, respecto de la interpretación de Colombia del artículo LVI. Tampoco considera la Corte que la ausencia de comentario alguno por parte de Nicaragua pueda constituirse como consentimiento de su parte. El hecho de que Nicaragua iniciara un procedimiento en el asunto relativo a Presuntas violaciones de derechos soberanos y espacios marítimos en el mar Caribe (Nicaragua c. Colombia) y en el presente asunto, dentro del año siguiente a la transmisión del aviso de denuncia de Colombia, confirma esta conclusión.

45. Pasando al argumento de Colombia respecto de los travaux préparatoires, la Corte considera que los travaux préparatoires del pacto demuestran que lo que pasó a ser el primer párrafo del artículo LVI se tomó del artículo 9 del Tratado General de Arbitraje Interamericano de 1929 y del artículo 16 de la Convención General de Conciliación Interamericana de 1929. El segundo párrafo se originó de una propuesta de Estados Unidos en 1938 que no se encontraba en los tratados de 1929. No obstante, los travaux préparatoires no indican el propósito exacto tras la adición de lo que pasó a ser el segundo párrafo del artículo LVI. La Corte también observa que, si la posición de Colombia respecto de la interpretación del segundo párrafo fuese correcta, la adición de este nuevo párrafo se hubiese aplicado para restringir el efecto de la disposición que, incluso antes de que Estados Unidos hiciera su propuesta, las partes estaban contemplando tomar del Tratado de 1929. Aun así, no hay ninguna indicación en los travaux préparatoires de que alguien considerara que la incorporación de este nuevo párrafo traería un cambio tan importante.

46. Por todas las razones anteriores, la Corte considera que la interpretación de Colombia del artículo LVI no puede ser aceptada. Tomando el artículo LVI en su conjunto, y a la luz de su contexto y el objeto y fin del Pacto, la Corte concluye que el artículo XXXI que confiere jurisdicción a la Corte se encontraba vigente entre las partes al momento en que la demanda en este asunto fue presentada. La terminación subsecuente del Pacto entre Nicaragua y Colombia no afecta la jurisdicción que existía al momento en que la demanda fue presentada. Por lo tanto, la primera excepción preliminar de Colombia debe ser rechazada.

\section{Tercera excepción preliminar}

47. En su tercera excepción preliminar, Colombia sostiene que la Corte carece de jurisdicción debido a que esta ya decidió sobre las 
pretensiones de Nicaragua en su fallo de 2012. Por lo tanto, Colombia argumenta que el principio de res judicata le prohíbe a la Corte examinar las pretensiones de Nicaragua nuevamente.

48. La Corte observa, en primer lugar, que no la vincula la forma en que las partes caractericen la excepción preliminar y que puede, de ser necesario, darle otra calificación -Interbandel (Suiza c. Estados Unidos de América), Excepciones preliminares, fallo, ICJ Reports 1959, p. 26-. La Corte considera que la tercera excepción preliminar de Colombia tiene las características de una excepción preliminar contra la admisibilidad, "en donde se alega la existencia de una razón legal, aun si existiere jurisdicción, por la cual la Corte debería declinar escuchar el caso, o más comúnmente, una de sus reclamaciones específicas" - Aplicación de la Convención para la Prevención y la Sanción del Crimen de Genocidio (Croacia c. Serbia), Excepciones preliminares, Fallo, ICJ Reports 2008, p. 456, para. 120; en el mismo sentido, ver Plataformas petroleras (República Islámica de Irán v. Estados Unidos de América), fallo, ICJ Reports 2003, p. 177, para. 29—. Así, la Corte abordará la tercera excepción preliminar de Colombia como una excepción de admisibilidad.

49. La Corte examinará ahora el principio de res judicata y su aplicación al subpárrafo 3 de la cláusula operativa del fallo de 2012, en el que la Corte determinó "que no puede aceptar la demanda formulada por la República de Nicaragua en el punto I(3) de sus conclusiones finales" -Diferendo territorial y marítimo (Nicaragua c. Colombia), ICJ Reports 2012 (II), p. 719_. En su pretensión final I(3), Nicaragua le solicitó a la Corte juzgar y declara que:

"[1] forma apropiada de delimitación dentro del marco legal y geográfico constituido por las costas continentales de Nicaragua y Colombia es una frontera de plataforma continental que divide en partes iguales los derechos superpuestos de ambas partes" (ibid., p. 636, para. 17).

La Corte describe esta reclamación como una petición "para definir 'una frontera de plataforma continental que divide en partes iguales los derechos superpuestos de ambas partes" (ibid., p. 664, para. 106).

50. Colombia considera que la primera pretensión de Nicaragua en su demanda del 16 de septiembre de 2013, mediante la cual da inicio a los presentes procedimientos, "no es más que una reencarnación del reclamo que ya había presentado Nicaragua en su pretensión final I(3)” de 2012, en la medida en que le pide a la Corte declarar "el curso preciso de la frontera marítima entre Nicaragua y Colombia en las áreas de la plataforma con- 
tinental que le pertenecen a cada una de las partes, más allá de la frontera determinada por la Corte en su fallo de 19 de noviembre de 2012".

51. Colombia agrega que la Corte, en su fallo de 2012, decidió que la pretensión contenida en la pretensión final I(3) era admisible, pero no la aceptó en sus méritos. Ese hecho impide a la Corte, en virtud del principio res judicata, conocer el presente caso.

52. Colombia argumenta que el destino de la segunda pretensión de la demanda del 16 de septiembre de 2013 está completamente vinculado con el de la primera. En su segunda pretensión, Nicaragua le pide a la Corte juzgar y declarar

"[1]os principios y reglas de derechos internacionales que determinan los derechos y deberes de los dos Estados en relación con el área de superposición de las pretensiones de las partes sobre la plataforma continental y el uso de sus recursos, mientras está pendiente la delimitación de la frontera marítima entre ellas más allá de las 200 millas náuticas desde la costa de Nicaragua”.

53. El principio res judicata está relacionado con la admisibilidad de la primera pretensión de Nicaragua. La segunda pretensión es objeto de la quinta excepción preliminar de Colombia, así que la Corte la examinará bajo ese título.

54. Incluso si las opiniones de las partes son concordantes frente a los elementos que constituyen el principio res judicata, las partes están en desacuerdo frente al significado de la decisión adoptada por la Corte en el subpárrafo 3 de la cláusula operativa de su fallo de 2012, y, por lo tanto, en lo que debe entenderse incluido dentro del alcance de la res judicata en esa decisión.

\section{El principio res judicata}

55. Las partes están de acuerdo en que el principio res judicata requiere de una identidad entre las partes (personae), el objeto (petitum) y la base legal (causa petendi). De forma similar aceptan que este principio está reflejado en los artículos 59 y 60 del Estatuto de la Corte. Estos artículos prevén, respectivamente, que "[l]a decisión de la Corte no es obligatoria sino para las partes en litigio y respecto del caso que ha sido decidido", y que "[e]l fallo será definitivo e inapelable. En caso de desacuerdo sobre el sentido o el alcance del fallo, la Corte lo interpretará a solicitud 
de cualquiera de las partes". Como la Corte lo subrayó en su fallo sobre excepciones preliminares en la Demanda de interpretación del fallo del 11 de junio de 1988 en el caso relativo a la Frontera terrestre y marítima entre Camerin y Nigeria (Camerún v. Nigeria) (Nigeria v. Camerún), "[e]l lenguaje y estructura del artículo 60 reflejan la primacía del principio res judicata" —ICJ Reports 1999 (1), p. 36, para. 12-.

56. Para Colombia, para que el principio res judicata aplique debe existir identidad entre las partes, el objeto y la base legal. Colombia añade que no le es dado a la Corte, habiendo decidido en la cláusula operativa del fallo de 2012, la cual posee fuerza de res judicata, que "no puede aceptar" la pretensión de Nicaragua por falta de evidencia, decidir en un fallo subsiguiente que acepta una pretensión idéntica.

57. Nicaragua considera que la identidad personae, petitum y causa petendi, aunque necesaria para la aplicación del principio res judicata, no es suficiente. Es necesario también que la cuestión presentada en un caso posterior haya sido previamente resuelta por la Corte de forma final y definitiva. Apoyándose en el fallo de fondo en el caso relativo a la Aplicación de la Convención para la Prevención y la Sanción del Crimen de Genocidio (Bosniay Herzegovina c. Serbia y Montenegro), Nicaragua argumenta que no se le puede atribuir fuerza de res judicata a un asunto que no ha sido decidido por la Corte. En consecuencia, Nicaragua considera que, para determinar si el fallo de 2012 tiene fuerza de res judicata en relación con la primera pretensión de Nicaragua en el presente caso, la cuestión central es si la Corte, en ese fallo, tomó una decisión sobre la delimitación de la plataforma continental más allá de las 200 millas náuticas desde la costa nicaragüense.

Para Nicaragua, no es suficiente demostrar que en el caso relativo al Diferendo territorialy marítimo (Nicaragua c. Colombia) las partes desarrollaron argumentos similares a aquellos en los que la primera pretensión se funda en estos procedimientos; es también necesario determinar que la Corte en efecto decidió sobre la base de esos argumentos.

58. La Corte recuerda que el principio res judicata, según se refleja en los artículos 59 y 60 de su Estatuto, es un principio general de derecho que protege tanto la función judicial de una corte o tribunal como a las partes de un caso que ha sido resuelto mediante un fallo de carácter final y sin apelación - Aplicación de la Convención para la Prevención y la Sanción del Crimen de Genocidio (Bosnia y Herzegovina c. Serbia y Montenegro), ICJ Reports 
2007 (I), pp. 90-91, para. 116-. Este principio determina el carácter final de las decisiones adoptadas en un caso particular - Aplicación de la Convención para la Prevención y la Sanción del Crimen de Genocidio (Bosnia y Herzegovina c. Serbia y Montenegro), ICJ Reports 2007 (I), p. 90, para. 115; Demanda de interpretación del fallo del 11 de junio de 1988 en el caso relativo a la Frontera terrestre y marítima entre Camerin y Nigeria (Camerún c. Nigeria), Excepciones preliminares (Nigeria c. Camerún), fallo, ICJ Reports 1999 (I), p. 36, para. 12; Canal de Corfú (Reino Unido c. Albania), Cálculo del monto de compensación, fallo, ICJ Reports 1949, p. 248-.

59. No es suficiente para la aplicación del principio resjudicata que se identifique el caso en cuestión, y que se indique que este tiene las mismas partes, objeto y base legal; también es necesario analizar el contenido de la decisión cuyo carácter definitivo debe garantizarse. Para la Corte, no es suficiente que exista identidad entre las pretensiones que se han presentado ante ella de manera sucesiva por las mismas partes; debe determinar además si y en qué medida la primera reclamación ya ha sido resuelta de manera definitiva.

60. La Corte subrayó en su fallo del 26 de febrero de 2007, emitido en el caso de la Aplicación de la Convención para la Prevención y la Sanción del Crimen de Genocidio (Bosnia y Herzegovina c. Serbia y Montenegro), que "[s]i una materia no ha sido resuelta de manera efectiva, de manera expresa o por implicación necesaria, entonces no puede atribuírsele ninguna fuerza de resjudicata; y que una decisión de carácter general deberá leerse en su contexto para determinar si una determinada materia estuvo o no contenida en ella" (ICJ Reports 2007 (I), p. 95, para. 126).

61. La decisión de la Corte está contenida en la cláusula operativa del fallo. Sin embargo, para discernir lo que está cubierto por la res judicata, puede ser necesario determinar el significado de la cláusula operativa por referencia al razonamiento expuesto en el fallo en cuestión. La Corte se enfrenta con una situación semejante en el presente caso, ya que las partes están en desacuerdo frente al contenido y alcance de la decisión que fue adoptada en el subpárrafo 3 de la cláusula operativa del fallo de 2012.

\section{La decisión adoptada por la Corte en su fallo del 19 de noviembre de 2012}

62. Las partes, tanto en sus alegatos orales como escritos, han presentado lecturas divergentes de la decisión adoptada en el subpárrafo 3 de la cláusula operativa del fallo de 2012, y de las razones que la soportan. 
Presentan conclusiones opuestas frente a lo que de manera específica cubre la decisión y sobre los problemas jurídicos que fueron resueltos de manera definitiva.

63. En esencia, Colombia intenta demostrar que las bases legales de la primera pretensión de Nicaragua, su petitum y su causa petendi, ya fueron presentados en el caso relativo al Diferendo territorial y marítimo (Nicaragua c. Colombia). Colombia alega que, habiendo intentando y fallado en cumplir con su carga de la prueba en ese caso, Nicaragua está pidiendo "otra oportunidad" en los actuales procedimientos. Colombia también argumenta que, dado que la Corte no aceptó los argumentos formulados por Nicaragua en su fallo de 2012, en virtud del efecto de la res judicata está impedida de conocer la demanda de Nicaragua en el presente caso.

64. Colombia alega que, en los procedimientos orales y escritos que precedieron al fallo de 2012, Nicaragua desarrolló argumentos idénticos a aquellos que esgrime en el presente caso. Colombia sostiene que esos argumentos ya habían sido presentados en la réplica, donde Nicaragua había reclamado una plataforma continental extendida sobre la base del artículo 76 de la Convención de las Naciones Unidas sobre el Derecho del Mar (Convemar) en virtud de criterios geológicos y geomorfológicos. Colombia agrega que, con base en la información preliminar aportada por ella a la CLPC, Nicaragua había procedido en ese entonces a reclamar una porción igual de las áreas en donde la plataforma continental de los dos Estados se superponía.

65. Colombia enfatiza que, durante los procedimientos orales que precedieron al fallo de 2012, ella refutó la "data tentativa" presentada por Nicaragua, y manifestó que esta era incapaz de respaldar la pretensión de Nicaragua. De acuerdo con Colombia, esa data no satisfacía los criterios exigidos por la CLPC, según se describe en sus directrices.

66. Colombia alega que Nicaragua no demostró, como era su obligación hacerlo, que su margen continental se extendía lo suficientemente lejos como para superponerse con la plataforma continental de la que es titular Colombia dentro de las 200 millas. Colombia sostiene que la Corte, después de declarar que la pretensión de Nicaragua era admisible, la resolvió de fondo en el año 2012, al decidir que no la aceptaba. Según Colombia, esa decisión, mediante la cual la Corte efectuó una delimitación plena de la frontera marítima entre las partes, tanto de manera expresa como por implicación necesaria, constituyó una decisión final. De esta forma, cuando la Corte sostuvo que "no estaba en posición de delimitar la plataforma continental" (parágrafo 129 del fallo de 2012), lo que quiso 
significar es que el examen de los hechos y argumentos presentados por Nicaragua la condujo a rechazar la pretensión.

67. Adicionalmente, Colombia cita los considerandos del fallo de 2012 para evidenciar que la decisión de la Corte "fue la culminación de un proceso de razonamiento".

Colombia refiere al parágrafo 126 del fallo, el cual, en su consideración, establece el derecho aplicable y deja claro que Nicaragua está vinculada por sus obligaciones bajo el artículo 76 de la Convemar. Colombia también se apoya en el parágrafo 129, en el que la Corte habría decidido que Nicaragua no estableció que tenía un margen continental que se extendía hasta superponerse con la plataforma continental a la que Colombia tenía derecho. A partir de su lectura de esta parte de los considerandos, Colombia concluye que la Corte en efecto resolvió la cuestión presentada ante ella en este caso.

68. Por su parte, Nicaragua alega que la decisión de la Corte de no aceptar su pretensión, según se expresa en el subpárrafo 3 de la cláusula operativa del fallo de 2012, no equivale a un rechazo de esa pretensión en los méritos. Lo que habría ocurrido es que la Corte de manera expresa se abstuvo de decidir el fondo de la cuestión porque Nicaragua no había completado su reclamación ante la CLPC.

69. Citando los considerandos en el fallo de 2012, Nicaragua sostiene que la Corte limitó su examen a la cuestión de si estaba "en una posición de determinar la frontera dentro de la plataforma continental dividiendo en partes iguales los derechos superpuestos entre las partes" (parágrafo 113 del fallo de 2012). Nicaragua argumenta que la Corte concluyó que no estaba en posición de delimitar la plataforma continental de las partes con base en la determinación del parágrafo 127 del fallo, según la cual Nicaragua solo le había suministrado "información preliminar" a la CLPC. De esta forma, la Corte no había estado en posición de delimitar porque Nicaragua no había establecido que su margen continental se extendía lo suficiente para crear una superposición de derechos (parágrafo 129 del fallo de 2012).

70. Nicaragua considera que el 24 de junio de 2013 cumplió con la obligación procedimental impuesta de conformidad con el artículo 76, párrafo 8, de la Convemar, de entregarle a la CLPC información sobre los límites de su plataforma continental más allá de las 200 millas náuticas, y 
que la Corte ahora tiene toda la información necesaria para llevar a cabo la delimitación y resolver la disputa.

71. Nicaragua admite que la frase "no puede aceptar" puede parecer 'ambigua' cuando se lee el subpárrafo 3 de la cláusula operativa únicamente, pero sostiene que esa ambigüedad se despeja cuando uno atiende a los considerandos de la decisión. Nicaragua agrega que el razonamiento es inseparable de la cláusula operativa por ser su necesario respaldo, y por ello debe ser tomado en consideración para determinar el alcance de los aspectos operativos del fallo. Se sigue del razonamiento del fallo que la cláusula operativa no toma posición en la delimitación más allá de las 200 millas náuticas. Por lo tanto, Nicaragua expresa que la Corte no está impedida, en el presente caso, para conocer de la pretensión relativa a la delimitación de la plataforma continental más allá de las 200 millas náuticas.

72. En primer lugar, la Corte observa que, aunque en su fallo de 2012 declaró que la pretensión de Nicaragua era admisible, lo hizo en respuesta a una objeción de admisibilidad presentada por Colombia en el sentido de que la pretensión era nueva y modificaba la materia objeto de la disputa. Sin embargo, no se sigue de ello que la Corte se haya pronunciado sobre los méritos de la pretensión relativa a la delimitación de la plataforma continental más allá de las 200 millas náuticas desde la costa de Nicaragua.

73. La Corte examinará ahora el contenido y alcance del subpárrafo 3 de la cláusula operativa del fallo de 2012. Como resultado del desacuerdo entre las partes frente al asunto, la Corte debe determinar el contenido de la decisión adoptada por ella en respuesta a la solicitud de Nicaragua para que se delimitara "la frontera de la plataforma continental mediante la división $[\ldots]$ de los derechos superpuestos [...] de las dos partes". Según lo indicó la Corte Permanente de Justicia Internacional en el contexto de una solicitud de interpretación, cuando existe una "diferencia de opiniones [entre las partes] frente a si un punto en particular ha sido o no ha sido decidido con fuerza vinculante [...] la Corte no puede evadir el deber que le incumbe de interpretar el fallo en la medida de lo necesario, para decidir sobre esa diferencia de opinión" - Interpretación de los fallos 7 y 8 (fábrica de Chorzow), fallo 11, 1927, PCIJ Serie A, No 13, pp. 11-12, citado por la Corte en el caso relativo a la Aplicación de la Convención para la Prevención y la Sanción del Crimen de Genocidio (Bosnia y Herzegovina c. Serbia y Montenegro), ICJ Reports 2007 (I), p. 95, para. 126, ver también Demanda de interpretación del fallo del 
15 de junio de 1962 en el caso relativo al Templo de Preah Vihear (Camboya c. Tailandia), (Camboya c. Tailandia), fallo, ICJ Reports 2013, p. 296, para. 34-. Esta declaración es relevante en el presente caso.

74. Nicaragua ha hecho gran énfasis en el hecho de que, en el subpárrafo 3 de la cláusula operativa, la Corte decidió que no "puede aceptar" la pretensión de Nicaragua contenida en su conclusión final I(3). Sin embargo, la Corte no está convencida de que el uso de esa fórmula conlleve la conclusión sugerida por Nicaragua. Tampoco está convencida del argumento de Colombia, según el cual la fórmula "no puede aceptar" equivale automáticamente a un rechazo de los méritos de la pretensión por parte de la Corte. Por lo tanto, la Corte no se detendrá en el significado de la frase "no puede aceptar", que en su consideración es una fórmula aislada en el fallo. En particular, la Corte determinará si el subpárrafo 3 de la cláusula operativa de su fallo de 2012 debe ser entendida como un rechazo directo de la pretensión de Nicaragua por ausencia de evidencia, como lo alega Colombia, o como una decisión de no pronunciarse frente a la pretensión porque un requisito procedimental e institucional no ha sido cumplido, como lo alega Nicaragua.

75. Para hacer esto, la Corte examinará el subpárrafo 3 de la cláusula operativa del fallo de 2012 en su contexto, es decir, por referencia a los considerandos que fueron fundamento para su adopción y que, por lo tanto, sirven para clarificar su significado. Como la Corte Permanente de Justicia Internacional lo reconoció en su opinión consultiva del 16 de mayo de 1925 en el Servicio Postal Polaco de Danzig, "todas las partes de un fallo que conciernan a un punto en disputa se explican y completan unas a otras y deben ser tomadas en consideración para determinar el significado y alcance preciso de la cláusula operativa" (PCIJ, Series B, $N^{\circ} 11$, p. 30). Además, "[a]l determinar el significado y alcance de una cláusula operativa del fallo original, la Corte, de acuerdo con su práctica, tendrá en consideración los considerandos del fallo en la medida en que arrojen luz sobre la interpretación adecuada de la cláusula operativa" —Demanda de interpretación del fallo del 15 de junio de 1962 en el caso relativo al Templo de Preah Vihear (Camboya c. Tailandia) (Camboya v. Tailandia), fallo, ICJ Reports 2013, p. 306, para. 68-. Aunque esa observación se hizo en el contexto de una demanda de interpretación de un fallo bajo el artículo 60 del Estatuto (algo que no se pretende en el presente caso), es importante recordar que el requisito de evaluar el significado de la parte operativa del fallo a través del examen de los considerados en los que se basa la parte operativa es de aplicación general. 
76. Los considerandos pueden referirse a puntos debatidos por las partes en el curso de los procedimientos. Sin embargo, el hecho de que un punto hubiere sido argumentado por las partes no necesariamente significa que fue decidido de manera definitiva por la Corte.

77. La Corte dedicó la sección IV de su fallo de 2012 a las "[c]onsideraciones a la solicitud de Nicaragua de delimitar la plataforma continental extendiéndose más allá de las 200 millas náuticas”. Esa sección está compuesta por los parágrafos 113 a 131 del fallo.

78. El parágrafo 113 define la cuestión examinada por la Corte sobre si "está en posición de determinar 'la frontera dividiendo en partes iguales los derechos a una plataforma continental que se superpone entre las partes" —ICJ Reports 2012 (II), p. 665, para. 113—. En los parágrafos 114 a 118, la Corte concluye que el derecho aplicable en el caso, entre un Estado parte de la Convemar y un Estado no parte (Colombia), es el derecho internacional consuetudinario relativo a la definición de la plataforma continental, según se refleja en el artículo 76, párrafo 1, de esa Convención. La Corte indicó que

"considerando el hecho de que la función de la Corte se limita a examinar si está en posición de llevar a cabo una delimitación marítima como la solicitada por Nicaragua, no necesita considerar si otras disposiciones del artículo 76 de Convemar forman parte de la costumbre internacional". (ibid., p. 666, para. 118).

79. Los parágrafos 119 a 121 resumen los argumentos de Nicaragua en relación con los criterios para determinar la existencia de una plataforma continental, las condiciones procedimentales señaladas en el artículo 76(8) de la Convemar para que un Estado pueda establecer el límite exterior de su plataforma continental más allá de las 200 millas náuticas y los pasos que Nicaragua había adoptado para ese propósito —ICJ Reports 2012 (II), pp. 666-667-.

80. Los parágrafos 122 a 124 presentan los argumentos de Colombia que contradicen la pretensión de Nicaragua para que se delimite la plataforma continental —ICJ Reports 2012 (II), pp. 667-668—. Colombia alegó que los derechos de Nicaragua a una plataforma continental extendida "nunca han sido reconocidos o presentados a la Comisión" (para. 122), y que "la información suministrada a la Corte [por Nicaragua] [...] basada en la 'información preliminar' presentada por Nicaragua a la Comisión, es "terriblemente deficiente" (ibid.). Colombia enfatizó que "la 'informa- 
ción preliminar' no cumple con los requisitos para que la Comisión haga su recomendación" (ibid.). Añadió que, en cualquier caso, Nicaragua no podría buscar respaldo en el artículo 76 para interferir con los derechos de otros Estados dentro de las 200 millas, máxime cuando esta "no [había] seguido los procedimientos de la Convención” (para. 124).

81. En los párrafos 126 y 127, respectivamente, la Corte señala que el hecho de que Colombia no sea parte de la Convemar "no releva a Nicaragua de sus obligaciones bajo el artículo 76 de esa Convención", y observa que, al momento del fallo de 2012, Nicaragua solo había presentado ante la CLPC 'información preliminar', la cual, según ella misma admitió, "no cumple con los requisitos" bajo el párrafo 8 del artículo 76 de la Convemar — ICJ Reports 2012 (II), p. 669-.

82. Al final de esa sección de sus considerandos, la Corte llega a la siguiente conclusión en el párrafo 129:

"No obstante, como Nicaragua, en el presente proceso, no ha establecido que posee un margen continental que se extiende tanto como para superponerse con el derecho de Colombia a 200 millas náuticas de plataforma continental, medidas desde la costa continental de Colombia, la Corte no está en posición de delimitar la plataforma continental entre Nicaragua y Colombia, como ha sido solicitado por Nicaragua, incluso haciendo uso de la fórmula general por ella propuesta". — ICJ Reports 2012 (II), p. 669-.

Este párrafo debe ser leído a la luz de aquellos que lo preceden en los considerandos del fallo de 2012. Tres aspectos de los considerandos sobresalen. Primero, aunque las partes hicieron extensas manifestaciones en relación con la evidencia geológica y geomorfológica de la extensión de la plataforma continental más allá de las 200 millas náuticas presentada por Nicaragua, el fallo no contiene un análisis de esa evidencia por parte de la Corte. Segundo, la Corte consideró (ver párrafo 78 arriba) que, a la luz de la naturaleza limitada de la tarea ante ella, no existía necesidad de considerar si las disposiciones del artículo 76 de la Convemar, el cual establece los criterios que un Estado debe reunir si pretende establecer límites en la plataforma continental más allá de las 200 millas náuticas contadas desde su costa, refleja el derecho internacional consuetudinario, el cual la Corte ya consideró que es el derecho aplicable en este caso. En tercer lugar, lo que la Corte sí enfatizó fue la obligación de Nicaragua, como parte de la Convemar y de conformidad con el artículo 76, párrafo 
8, de presentar información sobre los límites de la plataforma continental que reclama más allá de las 200 millas náuticas, ante la CLPC. Por cuanto al momento de emitirse el fallo de 2012 Nicaragua no había aún presentado esa información, la Corte concluyó en el párrafo 129 que "Nicaragua, en el presente proceso, no ha establecido que posee un margen continental que se extiende tanto como para superponerse con el derecho de Colombia a 200 millas náuticas de plataforma continental, medidas desde la costa continental de Colombia".

83. Las conclusiones de la Corte en el parágrafo 129 solo pueden entenderse a la luz de esos aspectos de sus considerandos. Estos indican que la Corte no había tomado una decisión sobre si Nicaragua tenía o no un derecho a una plataforma continental más allá de las 200 millas náuticas desde sus costas. Esto se confirma con el lenguaje del parágrafo 129 en sí mismo. La primera oración del parágrafo expresa que

"Nicaragua, en el presente proceso, no ha establecido que posee un margen continental que se extiende tanto como para superponerse con el derecho de Colombia a 200 millas náuticas de plataforma continental, medidas desde la costa continental de Colombia”.

La referencia al "presente proceso" no solo parece contemplar la posibilidad de futuros procedimientos, sino que la Corte allí alude únicamente al margen continental que se superpone con el derecho dentro de las 200 millas náuticas desde la costa continental colombiana. El fallo nada dice acerca de las áreas marítimas localizadas al este de la línea que se ubica a 200 millas náuticas desde las islas frente a la costa nicaragüense, más allá de las cuales la Corte no continuó su ejercicio de delimitación, y al occidente de la línea de 200 millas náuticas desde la costa continental colombiana. Sin embargo, la Corte estaba, en lo que concierne a estas áreas, enfrentada a reclamaciones opuestas por las partes en relación con la plataforma continental: Nicaragua, de un lado, reclamó una plataforma continental en estas áreas, y Colombia, de otro, sostuvo que tenía derechos en las mismas áreas marítimas generadas por las islas sobre las cuales reclamó soberanía, y la Corte de hecho las declaró bajo su soberanía.

84. Se sigue, por lo tanto, que aunque la Corte decidió, en el subpárrafo 3 de la cláusula operativa del fallo de 2012, que las reclamaciones de Nicaragua no podían aceptarse, lo hizo porque esta última no había cumplido aún con su obligación bajo el párrafo 8 del artículo 76 de la Convemar de depositar ante la CLPC la información sobre los límites de su 
plataforma continental más allá de las 200 millas náuticas, según lo exige esa disposición y el artículo $4^{\circ}$ del anexo II de la Convemar.

\section{Aplicación del principio res judicata en el caso}

85. La Corte ha clarificado el contenido y alcance del subpárrafo 3 de la cláusula operativa del fallo de 2012, tomando en consideración las oposiciones divergentes expresadas por las partes sobre el asunto. $\mathrm{Ha}$ determinado que la delimitación de la plataforma continental más allá de las 200 millas náuticas desde la costa nicaragüense estaba condicionada a la presentación por parte de Nicaragua de la información sobre los límites de su plataforma continental más allá de las 200 millas náuticas, según se estipula en el párrafo 8 del artículo 76 de la Convemar, ante la CLPC. Por lo tanto, la Corte no resolvió la cuestión de la delimitación en 2012 porque no estaba, en ese momento, en posición de hacerlo.

86. La Corte recuerda que, en su demanda, Nicaragua indica que el 24 de junio de 2013 le proporcionó a la CLPC la "información final". Este hecho no ha sido refutado por Colombia.

87. Por lo tanto, la Corte considera que la condición impuesta por ella en el fallo de 2012 para poder examinar la pretensión contenida en la conclusión final $\mathrm{I}(3)$ ha sido cumplida en este caso.

88. La Corte concluye que no está impedida en virtud del principio res judicata de decidir sobre la demanda presentada por Nicaragua el 16 de septiembre de 2013. A la luz de lo anterior, la Corte decide que la tercera excepción preliminar de Nicaragua debe ser rechazada.

\section{Cuarta excepción preliminar}

89. Colombia funda su cuarta excepción preliminar en que, en su fallo de 2012, la Corte rechazó la solicitud de delimitación de la plataforma continental de las partes más allá de las 200 millas náuticas y estableció la frontera marítima entre los espacios marítimos de cada parte. De acuerdo con Colombia, esa decisión fue "definitiva y sin apelación" de conformidad con el artículo 60 del Estatuto. Por esta razón, lo que busca Nicaragua a través de la demanda del 16 de septiembre de 2013 es 'apelar' el fallo previo, o que este sea revisado.

90. Nicaragua no le pide a la Corte revisar el fallo de 2012, y tampoco enmarca su demanda como una ‘apelación'. En consecuencia, la Corte encuentra que la cuarta excepción preliminar de Colombia es infundada. 


\section{Segunda excepción preliminar}

91. La segunda excepción preliminar de Colombia ataca el argumento de Nicaragua, según el cual, con independencia de la aplicabilidad del artículo XXXI del Pacto de Bogotá entre Colombia y Nicaragua, la Corte es titular de una jurisdicción continuada sobre la materia objeto de la demanda. Según Nicaragua, esta jurisdicción continuada está basada en la jurisdicción de la Corte en el caso relativo al Diferendo territorial y marítimo (Nicaragua c. Colombia), dado que la Corte, en el fallo de 2012, no resolvió de forma definitiva la cuestión de la delimitación de la plataforma continental entre Nicaragua y Colombia en el área más allá de las 200 millas náuticas desde la costa de Nicaragua, de manera que esta cuestión permanece pendiente.

92. Colombia niega que una tal jurisdicción continuada pueda existir en el presente caso. En opinión de Colombia, a menos de que la Corte se reserve expresamente su jurisdicción, lo que no hizo en el fallo de 2012, no existe fundamento con base en el cual la Corte pueda ejercer jurisdicción continua una vez ha sido emitido el fallo de fondo. De acuerdo con Colombia, el Estatuto prevé solo dos procedimientos a través de los cuales la Corte puede actuar, sin una base independiente de jurisdicción, en relación con materias que han sido previamente objeto de un fallo entre las mismas partes: demanda de interpretación del fallo anterior bajo el artículo 60 del Estatuto y demanda de revisión de un fallo previo bajo el artículo 61. En atención a que el presente caso no se enmarca en el artículo 60 ni en el artículo 61, Colombia alega que la Corte carece de jurisdicción a la luz de la base adicional presentada por Nicaragua.

93. Nicaragua rechaza el análisis de Colombia. De acuerdo con Nicaragua, la Corte tiene una obligación de ejercer su jurisdicción de forma plena en cualquier caso que de manera adecuada se presente ante ella. La Corte declinó, en el fallo de 2012, ejercer su jurisdicción en relación con aquella parte del caso de Nicaragua que constituye la materia objeto de los actuales procedimientos aludiendo a razones que, de conformidad con Nicaragua, ya no aplican. Nicaragua sostiene que la Corte debe ahora ejercer su jurisdicción, la cual posee desde el fallo de 2012. En consecuencia, Nicaragua argumenta que la Corte posee una jurisdicción continua sobre los asuntos incoados mediante la actual demanda, con irrelevancia de si se reservó de forma expresa su jurisdicción en el caso previo. Nicaragua sostiene que esta base de jurisdicción es adicional a la conferida por el artículo XXXI del Pacto de Bogotá. 
94. La Corte recuerda que ya ha sostenido (ver parágrafos 46, 88 y 90, arriba) que el artículo XXXI del Pacto de Bogotá le confiere jurisdicción en relación con los actuales procedimientos, ya que la demanda de Nicaragua fue presentada antes de que el Pacto de Bogotá cesara en su vigor entre Nicaragua y Colombia. Por lo tanto, resulta innecesario considerar si la base adicional de jurisdicción de Nicaragua existe. En consecuencia, no existe fundamento para que la Corte se pronuncie sobre la segunda excepción preliminar elevada por la República de Colombia.

\section{Quinta excepción preliminar}

95. En subsidio, Colombia alega que, en la hipótesis en que sus otras cuatro excepciones preliminares fueren rechazadas, debería considerarse que en todo caso las dos pretensiones presentadas en la demanda de Nicaragua son inadmisibles. Colombia considera que la primera pretensión es inadmisible debido a que Nicaragua no ha conseguido una recomendación en relación con el establecimiento de los límites exteriores de la plataforma continental por parte de la CLPC; la segunda pretensión es inadmisible porque, si fuere otorgada, la decisión de la Corte resultaría inaplicable y concerniría a una disputa inexistente.

96. La Corte examinará de manera individual la admisibilidad de cada una de las dos pretensiones.

\section{Excepción preliminar frente a la admisibilidad de la primera pretensión de Nicaragua}

97. En su primera pretensión, Nicaragua le pide a la Corte que determine "el curso preciso de la frontera marítima entre Nicaragua y Colombia en las áreas de la plataforma continental que le pertenecen a cada una de las partes más allá de la frontera determinada por la Corte en su fallo del 19 de noviembre de 2012". Colombia sostiene que "la [Corte] no puede considerar la demanda presentada por Nicaragua porque la CLPC no ha establecido que las condiciones para determinar la extensión del borde exterior de la plataforma continental de Nicaragua más allá de la línea de 200 millas náuticas se encuentran satisfechas y, en consecuencia, no ha emitido una recomendación". 
98. Citando el artículo 76, párrafo 1, de la Convemar, Colombia argumenta que existe una distinción entre el derecho de un Estado costero a la plataforma continental hasta una distancia de 200 millas náuticas desde las líneas de base, que existe de forma automática, ipso jure, y sus derechos sobre la plataforma continental más allá de las 200 millas náuticas, hasta el borde exterior del margen continental, los cuales son objeto de las condiciones previstas en los párrafos 4, 5 y 6 de ese artículo.

99. Colombia reconoce que, de acuerdo con el artículo 76, le corresponde al Estado costero, como Estado parte de la Convemar, establecer los límites exteriores de su plataforma continental más allá de las 200 millas náuticas. Sin embargo, considera también que, para hacerlo, este último debe seguir el procedimiento prescrito en el párrafo 8 del mismo artículo. En particular, el Estado costero relevante requiere una recomendación de la CLPC para establecer, sobre esa base, un límite exterior "definitivo y obligatorio".

100. Así, en la posición de Colombia, Nicaragua, como Estado parte de la Convemar, debe obtener una recomendación por parte de la CLPC si desea reclamar derechos sobre la plataforma continental más allá de las 200 millas náuticas. Colombia agrega que, en el presente caso, Nicaragua "solicita que se delimite la plataforma continental entre costas opuestas, lo cual no puede hacerse sin primero identificar la extensión, o límite, de la titularidad de cada Estado sobre la plataforma". La ausencia de una recomendación de la CLPC debe, por lo tanto, resultar en la inadmisibilidad de la primera pretensión contenida en la demanda del 16 de septiembre de 2013.

101. Nicaragua responde que un Estado costero dispone de derechos inherentes sobre la plataforma continental, los cuales existen ipso facto y $a b$ initio, y que sus propios derechos sobre la plataforma continental se generan de forma automática, ipso jure, por operación del derecho. Además, la CLPC se ocupa únicamente de la ubicación precisa de los límites exteriores de la plataforma continental, y no otorga o reconoce los derechos de un Estado costero sobre su plataforma y no está en capacidad de delimitar las fronteras en la plataforma.

102. De acuerdo con Nicaragua, el rol de la CLPC es proteger el patrimonio común de la humanidad contra posibles intrusiones por parte de Estados costeros. Agrega que, aunque el rol de la CLPC es proteger el 
patrimonio común frente a reclamos excesivos, sus recomendaciones no son vinculantes frente al Estado reclamante. Si el Estado está en desacuerdo con las recomendaciones, puede presentar una reclamación revisada o nueva.

103. Más aún, Nicaragua considera que la práctica estatal demuestra que los Estados han celebrado acuerdos de delimitación sobre la plataforma continental más allá de las 200 millas náuticas en ausencia de recomendaciones de la CLPC. En ciertos casos se han celebrado esos acuerdos sin haber presentado información ante la CLPC. En consecuencia, Nicaragua argumentó que una corte o tribunal internacional estarían igualmente en posición de resolver una disputa de delimitación en relación con la plataforma continental extendida antes de que la CLPC haya emitido su recomendación.

104. Nicaragua agrega que, en el evento de que se llegare a generar disputa sobre su plataforma continental más allá de las 200 millas náuticas, la CLPC, de acuerdo con sus propias reglas y práctica establecida, no podría analizar la recomendación de Nicaragua. Si la Corte decidiera rehusarse a actuar porque la CLPC no ha emitido esa recomendación, el resultado sería un impasse, como ha sido puesto de presente por el Tribunal Internacional sobre el Derecho del Mar en su fallo del 14 de marzo de 2012 en la Disputa relativa a la delimitación de la frontera marítima entre Bangladesh y Myanmar en la Bahia de Bengala (Bangladesh/Myanmar).

105. La Corte ya ha establecido (ver parágrafo 82) que Nicaragua estaba bajo una obligación, de conformidad con el párrafo 8 del artículo 76 de la Convemar, de presentar información sobre los límites de su plataforma continental más allá de las 200 millas náuticas ante la CLPC. La Corte sostuvo, en su fallo de 2012, que Nicaragua debía presentar esa información como un prerrequisito para la delimitación de la plataforma continental más allá de las 200 millas náuticas por parte de la Corte.

106. La Corte debe ahora determinar si una recomendación efectuada por la CLPC, de conformidad con el artículo 76, párrafo 8, de la Convemar, es un requisito para que la Corte pueda conocer de la demanda presentada por Nicaragua en 2013.

107. La Corte observa que Nicaragua, como Estado parte de la Convemar, está bajo la obligación de transmitirle a la CLPC la información sobre los límites de su plataforma continental más allá de las 200 millas náuticas, según se prevé en el párrafo 8 del artículo 76 de la Convemar, mientras que la emisión de una recomendación, después de examinada la información, es una prerrogativa de la CLPC. 
108. Cuando la CLPC emite sus recomendaciones sobre cuestiones relativas al borde exterior de la plataforma continental de los Estados costeros, esos Estados establecen, sobre esa base, límites que, según lo prevé el párrafo 8 del artículo 76 de la Convemar, son "definitivos y obligatorios" para los Estados partes de ese instrumento.

109. La Corte además enfatiza que este procedimiento autoriza a la CLPC a cumplir su rol principal, que consiste en asegurar que la plataforma continental de un Estado costero no se extienda más allá de los límites previstos en los párrafos 4, 5 y 6 del artículo 76 de la Convemar, evitando de esa forma que la plataforma continental usurpe "la zona y sus recursos", los cuales son "patrimonio común de la humanidad" (Convemar, artículo 136).

110. Dado que el rol de la CLPC versa únicamente sobre la delineación del borde exterior de la plataforma continental, y no sobre la delimitación, el artículo 76 de la Convemar establece en su párrafo 10 que "[1]as disposiciones de este artículo no prejuzgan la cuestión de la delimitación de la plataforma continental entre Estados con costas adyacentes o situadas frente a frente".

111. En efecto, el artículo 76 de la Convemar, que contiene la definición de plataforma continental, establece, en vista de la complejidad técnica de la tarea de determinar el borde exterior del margen continental y de los límites exteriores de la plataforma continental, una comisión cuya función, según el anexo II de la Convemar, es "[e]xaminar los datos y otros elementos de información presentados por los Estados ribereños respecto de los límites exteriores de la plataforma continental cuando ésta se extienda más allá de 200 millas marinas y hacer recomendaciones de conformidad con el artículo 76 [de la Convemar]" (artículo $3^{\circ}$, párrafo 1(a) del anexo II de la Convemar).

112. El procedimiento ante la CLPC se relaciona con la delineación de los límites de la plataforma continental y, por ende, con la determinación de la extensión del lecho marino bajo jurisdicción nacional. Es distinto de la delimitación de la plataforma continental, la cual está gobernada por el artículo 83 de la Convemar y que se efectúa por acuerdo entre los Estados concernidos, o mediante los mecanismos de resolución de controversias.

113. No obstante el hecho de que la Convemar distingue entre el establecimiento de los límites exteriores de la plataforma continental y su delimitación entre Estados con costas adyacentes u opuestas, es posible que las dos operaciones tengan impacto la una en la otra. En su reglas internas (artículo 46 y anexo 1), la CLPC ha establecido procedimientos, 
de acuerdo con el artículo $9^{\circ}$ del anexo II de la Convemar, para asegurar que sus acciones no perjudiquen cuestiones de delimitación.

114. Por lo tanto, la Corte considera que, ya que la delimitación de la plataforma continental más allá de las 200 millas náuticas puede llevarse a cabo con independencia de una recomendación por parte de la CLPC, esta última no es un prerrequisito que deba satisfacerse por un Estado parte de la Convemar antes de que pueda pedirle a la Corte que resuelva una controversia con otro Estado sobre esa delimitación.

115. A la luz de lo anterior, la Corte encuentra que la excepción preliminar de admisibilidad contra la primera pretensión de Nicaragua debe ser rechazada.

\section{Excepción preliminar de admisibilidad contra la segunda pretensión de Nicaragua}

116. En su segunda solicitud, Nicaragua le pide a la Corte establecer "[1]os principios y reglas del derecho internacional que determinan los derechos y deberes de los dos Estados en relación con el área de reclamaciones superpuestas sobre la plataforma continental y la utilización de sus recursos, mientras se encuentra pendiente la delimitación de la frontera marítima entre estas más allá de las 200 millas náuticas desde la costa de Nicaragua”.

117. Colombia alega que la segunda pretensión de Nicaragua invita a la Corte a emitir un pronunciamiento mientras se encuentra pendiente su decisión sobre la primera pretensión, y que, dado que la Corte tendría que decidir sobre las dos pretensiones de manera simultánea, no podría aceptar la segunda pretensión porque carecería de objeto.

118. Colombia también considera que la segunda pretensión de Nicaragua es una solicitud disfrazada de medidas provisionales y que, por lo tanto, debería rechazarse.

119. Finalmente, Colombia argumenta que no existe una disputa entre las partes relativa al régimen legal hipotético que debería aplicarse mientras se encuentra pendiente la decisión sobre la frontera marítima más allá de las 200 millas náuticas desde la costa de Nicaragua. 
120. Nicaragua considera que la relevancia de la segunda pretensión depende de la decisión de fondo de la Corte en relación con la cuestión de la delimitación de la plataforma continental entre las partes más allá de las 200 millas náuticas desde la costa de Nicaragua. Sostiene que los argumentos sobre el contenido de los deberes de limitación y cooperación que incumben a las partes son un asunto de la etapa de méritos, y no de las excepciones preliminares.

121. Nicaragua no está de acuerdo con que la segunda pretensión constituye una solicitud disfrazada de medidas provisionales. Asegura que existe en efecto una disputa entre las partes, ya que Colombia niega que Nicaragua tenga cualquier derecho legal —o incluso una reclamación— más allá de las 200 millas náuticas desde su costa. De acuerdo con Nicaragua, su segunda pretensión es una cuestión que está subsumida dentro de la disputa que constituye la materia objeto del presente caso.

122. La Corte observa que, en su segunda solicitud, Nicaragua le invita a determinar los principios y reglas del derecho internacional que gobiernan la situación que será clarificada y resuelta solo en la etapa de fondo del caso.

123. Sin embargo, no le corresponde a la Corte determinar el derecho aplicable en relación con una situación hipotética. La Corte recuerda que su función es "establecer el derecho, pero puede pronunciar un fallo únicamente en relación con casos concretos en donde exista al momento de la adjudicación una controversia vigente que involucre un conflicto de intereses legales entre las partes" - Camerín del Norte (Camerín c. Reino Unido), Excepciones preliminares, fallo, ICJ Reports 1963, pp. 33-24-.

124. Este no es el caso en esta etapa de los procedimientos en relación con la segunda pretensión de Nicaragua. Esta solicitud no se relaciona con una disputa vigente entre las partes, esto es, "un desacuerdo sobre un punto de hecho o de derecho, un conflicto de posiciones jurídicas o de intereses entre las dos partes" —Concesiones palestinas de mavrommatis, fallo 12, 1924, PCIJ, Series $A, N^{\circ}$ 2, p. 11-, tampoco se especifica qué es lo que se le pide hacer a la Corte exactamente.

125. De conformidad con lo anterior, la Corte decide que la objeción preliminar de admisibilidad de la segunda pretensión de Nicaragua debe ser aceptada. 
126. Por estas razones,

la Corte

(1) (a) Unánimemente,

rechaza la primera excepción preliminar presentada por la República de Colombia;

(b) Por ocho votos contra ocho, con el voto de desempate del Presidente,

rechaza la tercera excepción preliminar presentada por la República de Colombia;

A FAVOR: presidente Abraham; jueces Owada, Tomka, Bennouna, Greenwood, Sebutinde, Gevorgian; juez ad hoc Skotnikov;

EN CONTRA: vicepresidente Yusuf; jueces Cançado Trindade, Xue, Donoghue, Gaja, Bhandari, Robinson; juez ad hoc Brower;

(c) Unánimemente,

rechaza la cuarta excepción preliminar presentada por la República de Colombia;

(d) Unánimemente,

encuentra que no existe fundamento para decidir sobre la segunda excepción preliminar presentada por la República de Colombia;

(e) Por ocho votos contra cinco,

rechaza la quinta excepción preliminar presentada por la República de Colombia en lo que esta concierne a la primera pretensión presentada por Nicaragua en su demanda.

A FAVOR: presidente Abraham; jueces Owada, Tomka, Bennouna, Greenwood, Donoghue, Gaja, Sebutinde, Gevorgian; jueces ad hoc Brower, Skotnikov;

EN CONTRA: vicepresidente Yusuf; jueces Cançado Trindade, Xue, Bhandari, Robinson;

(f) Unánimemente,

acepta la quinta excepción preliminar presentada por la República de Colombia en lo que esta concierne a la segunda pretensión presentada por Nicaragua en su demanda;

(2) (a) Unánimemente,

decide que tiene jurisdicción, sobre la base del artículo XXXI del Pacto de Bogotá, para conocer de la primera pretensión presentada por la República de Nicaragua; 


\section{0}

(b) Por ocho votos contra ocho, con el voto de desempate del Presidente,

decide que la primera pretensión presentada por la República de Nicaragua en su demanda es admisible.

A FAVOR: presidente Abraham; jueces Owada, Tomka, Bennouna, Greenwood, Sebutinde, Gevorgian; juez ad hoc Skotnikov;

EN CONTRA: vicepresidente Yusuf; jueces Cançado Trindade, Xue, Donoghue, Gaja, Bhandari, Robinson; juez ad hoc Brower.

Hecho en francés e inglés, siendo el texto en francés auténtico, en el Palacio de la Paz, La Haya, este 17 de marzo de 2016, en tres copias, una de las cuales será depositada en los archivos de la Corte y las otras dos transmitidas a los gobiernos de la República de Nicaragua y de la República de Colombia, respectivamente.

Firmó: Ronny ABRAHAM,

Presidente

Firmó: Philippe Couvreur, Secretario 


\section{Traducción de los resúmenes de las opiniones de los jueces preparados por la Secretaría de la Corte Internacional de Justicia}

\section{Opinión disidente conjunta del vicepresidente Yusuf, jueces Cançado Trindade, Xue, Gaja, Bhandari, Robinson, y juez ad hoc Brower}

\section{Introducción}

1. Los siete jueces que escribieron la opinión disidente conjunta lamentan que la Corte estuviese dividida respecto del contenido y alcance de una decisión que fue adoptada por unanimidad por la Corte hace cuatro años. Ellos son de la opinión de que la excepción de Colombia basada en el principio res judicata debió ser aceptada y la demanda introductiva de instancia de Nicaragua rechazada por ser inadmisible, al no estar permitida por el principio res judicata.

\section{El principio res judicata en la jurisprudencia de la Corte y su aplicación en el presente caso}

2. La opinión disidente conjunta describe el entendimiento de sus autores de la res judicata. Esta concepción considera la res judicata como un principio general, el cual está reflejado en los artículos 59 y 60 del Estatuto de la Corte, según el cual "las decisiones de la Corte no solo son obligatorias para las partes, son además definitivas, en el sentido de que no pueden ser reabiertas por las partes respecto de las cuestiones que han sido decididas". Es un principio que actúa para prevenir una subsiguiente reclamación si existe identidad de partes, identidad de causa e identidad de objeto respecto de una reclamación anterior que ha sido adjudicada.

3. No obstante, los siete jueces son conscientes del hecho de que, a pesar que las partes están de acuerdo en estos elementos, se encuentran en desacuerdo respecto de lo que la Corte determinó finalmente en su decisión de 2012 en el Diferendo territorial y marítimo (Nicaragua c. Colombia). 
Son de la opinión que esto debe buscarse en el dispositif de la decisión, en el que opera la res judicata, así como en los elementos de las razones de la Corte que son "inseparables" de la parte operativa de una decisión o que constituyen una "condición esencial de la decisión de la Corte".

\section{El dispositif de la decisión de 2012 del Diferendo territorial y marítimo}

4. La opinión disidente conjunta recuerda que la Corte indicó en el dispositif de su decisión de 2012: "La Corte [...] [e]ncuentra que no puede aceptar la demanda formulada por la República de Nicaragua en el punto I(3) de sus conclusiones finales" - ICJ Reports 2012 (II), p. 719, para. 251(3)—. Nicaragua le ha solicitado a la Corte que juzgue y declare que "[l]a forma apropiada de delimitación dentro del marco legal y geográfico constituido por las costas continentales de Nicaragua y Colombia es una delimitación de la plataforma continental dividiendo en partes iguales los derechos que se sobreponen en cuanto a la plataforma continental de ambas partes" (ibid., p. 636, para. 17).

5. La opinión disidente conjunta, tras haber estudiado las decisiones de la Corte en las que la frase "no puede aceptar" ha sido usada, concluye que la Corte la ha utilizado de manera consistente para rechazar la pretensión o solicitud de una parte. Así, sus autores son de la opinión de que la Corte rechazó la pretensión final I(3) en 2012. Por consiguiente, como la Corte rechazó la pretensión en el parágrafo operativo de su decisión de 2012, tomó una decisión a la que aplica la res judicata.

6. En el presente asunto, la primera pretensión de Nicaragua a la Corte es juzgar y declarar "el curso preciso de la frontera marítima entre Nicaragua y Colombia en las áreas de la plataforma continental que pertenecen a cada uno más allá de las fronteras establecidas por la Corte en la decisión de 2012" (demanda introductoria de instancia, de ahora en adelante 'DN', para. 12). El parágrafo 11 de la demanda introductoria de instancia indica que la alegada plataforma continental extendida de Nicaragua "incluye un área más allá de la zonas de 200 millas náuticas de Nicaragua y que en parte se superpone con el área que se encuentra dentro de las 200 millas náuticas de la costa de Colombia —DN, para. 11(c)—, y que este derecho a una plataforma continental extendida existe a la luz del derecho internacional consuetudinario y las disposiciones de la Convemar —DN, para. 11(a)_”. 
7. Los siete jueces son de la opinión de que la pretensión final I(3) de Nicaragua en el asunto del Diferendo territorial y marítimo, y la primera pretensión en la demanda introductoria de instancia de Nicaragua en el presente caso tienen ambas el mismo objeto (la delimitación de un derecho a plataforma continental extendida que se superpone con el derecho de Colombia a 200 millas náuticas, medidas desde la costa continental de esta última), el mismo fundamento jurídico (que este derecho existe como derecho internacional consuetudinario y en la Convemar) y se refiere a las mismas partes. Por lo tanto, Nicaragua intenta presentar una pretensión contra la misma parte y con el mismo fundamento jurídico. Como el estudio del uso de la frase "no puede aceptar" en la opinión disidente conjunta lo demuestra, la Corte rechazó la pretensión I(3) de Nicaragua en su decisión de 2012. La primera pretensión de Nicaragua en su demanda introductoria de instancia es, por lo tanto, un caso ejemplar de una pretensión no permitida por la res judicata.

\section{Las razones de la Corte en la decisión de 2012 del Diferendo territorial y marítimo}

8. Los siete jueces de la opinión disidente conjunta lamentan que la mayoría no examinara el uso de la frase "no puede aceptar" y no diera así efecto a las palabras contenidas en el dispositif de la decisión de 2012. La aproximación de la mayoría se basa en examinar las razones de la Corte en esa decisión y no su dispositif. Sin embargo, los siete jueces sostienen que incluso esas razones respaldan el argumento de que la Corte rechazó la pretensión de Nicaragua en 2012 porque no demostró la existencia de una plataforma continental extendida que se superponga con el derecho de Colombia a 200 millas náuticas, medidas desde la costa continental de esta última.

9. El lenguaje usado por la Corte en el parágrafo 129 de su decisión de 2012 es claro en establecer que la Corte rechazó la pretensión de Nicaragua porque ella "no estableció que tiene un margen continental que se extienda lo suficiente para superponerse con el derecho de Colombia a 200 millas náuticas" (énfasis por fuera del texto) (en el texto francés: "le Nicaragua n'ayant pas [...] apporté la preuve que sa marge [...]").

10. Esta conclusión también está respaldada por el rechazo de parte de la Corte de la propuesta de Nicaragua de una "fórmula general" en la decisión de 2012, según la cual solicitó a la Corte delimitar los derechos de plataforma continental que se superponen, tal como "la frontera es 
la línea media entre el límite exterior de la plataforma continental de $\mathrm{Ni}$ caragua de acuerdo con la Convemar, artículo 76, y el límite exterior de la zona de 200 millas de Colombia" (ICJ Reports 2012 (II), p. 669, para. 128). La Corte encontró que, "incluso haciendo uso de la fórmula general propuesta" por Nicaragua (ibid., p. 669, para. 129; énfasis por fuera del texto), no estaba en posición de efectuar la delimitación entre las partes. La única razón que la Corte tuvo para retirar y rechazar la "fórmula general", distinta a la pretensión final I(3), era que la anterior pretensión se basaba únicamente en la existencia de una plataforma continental que se superponía con el derecho a 200 millas náuticas de Colombia, y no en la delineación de sus límites exteriores.

11. Así, el rechazó por parte de la Corte de la solicitud de Nicaragua no estaba, como lo sostuvo la mayoría, basada en la falta por parte de Nicaragua de depositar la información en la CLPC de acuerdo con el artículo 76(8) de la Convemar. Ciertamente, incluso Nicaragua durante la fase oral del procedimiento del presente caso admitió que la Corte decidió en 2012 que ella no había establecido la existencia de una plataforma continental extendida que se superponga con el derecho de Colombia a 200 millas náuticas, medidas desde la costa continental de esta última.

12. Más aún, y contrario a la conclusión de la mayoría, la Corte nunca indicó que existía un requisito procedimental que corresponde a Nicaragua, de presentar la información a la CLPC antes de que la Corte pueda proceder con la delimitación, así como la Corte tampoco sugirió que Nicaragua podría regresar a la Corte una vez ella hubiese realizado la presentación ante la CLPC.

13. Los siete jueces deben, por lo tanto, concluir que la falta de Nicaragua de probar la existencia de una plataforma continental que se superpone con el derecho de Colombia a 200 millas náuticas constituía la base de la decisión adoptada por la Corte en 2012 respecto de la delimitación. Este es el elemento más importante de las razones de la Corte de aquellos que son la base de la cláusula operativa a la que la res judicata aplica.

14. La segunda pretensión de Nicaragua en el presente asunto solicita a la Corte juzgar y declarar "los principios y reglas de derecho internacional que determinan los derechos y deberes de los dos Estados en relación con el área donde se superponen los reclamos de plataforma continental y el uso de sus recursos, a la espera de la delimitación de la frontera marítima entre ellos más allá de las 200 millas náuticas desde la costa de Nicaragua" (DN, para. 12). Esta es una reformulación de la "fórmula general" propuesta a la Corte por Nicaragua en el proceso del Diferendo territorialy 
marítimo. Tal y como ocurre con la primera pretensión de Nicaragua en el presente asunto, la segunda pretensión está prohibida por la res judicata.

\section{La incoherencia en el requisito procedimental introducido por la mayoría}

15. La mayoría ha determinado la existencia de un requisito procedimental en la decisión de 2012, según el cual un Estado ribereño está obligado a presentar la información a la CLPC de acuerdo con el artículo 76(8) de la Convemar, como un prerrequisito para la delimitación de un derecho a plataforma continental extendida entre Nicaragua y Colombia. Por lo tanto, enmarca la presentación de la información a la CLPC de acuerdo con el artículo 76(8) como un requisito de admisibilidad; en otras palabras, como una "contención de que existe una razón jurídica, aun cuando hay jurisdicción, por la cual la Corte debe rehusarse a escuchar el caso, o más usualmente, una pretensión específica" - Aplicación de la Convención para Preveniry Sancionar el Delito de Genocidio (Croacia c. Serbia), Excepciones preliminares, fallo, ICJ Reports 2008, pp. 456, para. 120-.

16. Sin embargo, en la decisión de 2012, la cuestión sobre la admisibilidad de la pretensión final I(3) de Nicaragua fue expresamente alegada por Colombia, quien argumentó que la solicitud de delimitar una plataforma continental extendida no se encontraba implícita en la demanda introductoria de instancia de Nicaragua y tampoco era un aspecto que surgiera directamente del objeto-materia de la controversia —-ICJ Reports 2012 (II), p. 664, para. 107- La Corte rechazó la excepción de Colombia y declaró admisible la pretensión I(3) de Nicaragua.

17. La línea argumentativa de la mayoría en el presente asunto deja a la Corte en una posición extraña. Si uno acepta la opinión de la mayoría en el presente asunto, la Corte no debió, en el proceso de 2012, aceptar como admisible la pretensión I(3) y no debió proceder a analizar esa pretensión en sus aspectos de fondo. Por otra parte, si uno acepta - como la Corte hizo en 2012 - que la pretensión I(3) era admisible, entonces la lógica indica que la presentación a la CLPC de acuerdo con el artículo 76(8) de la Convemar no puede ser un prerrequisito para poder adjudicar respecto de una solicitud de delimitación de plataforma continental extendida.

18. La posición de la mayoría no es únicamente inconsistente con la decisión de 2012, también es inconsistente con el texto del artículo 76(8) de la Convemar. Esta disposición puede dividirse en partes, cada una con el imperativo "debe” en la versión en inglés de la Convención: el Estado 
ribereño debe presentar la información; la CLPC debe hacer una recomendación; y los límites establecidos tomando como base la recomendación de la CLPC deben ser finales y obligatorios. No es claro por qué la mayoría considera que la primera parte de este artículo constituye un prerrequisito para efectuar la delimitación y los otros dos no; claramente, no existe una base textual para tal lectura.

\section{El propósito de presentar la información de acuerdo con el artículo 76 de la Convemar y el artículo $4^{\circ}$ de su anexo II}

19. Según las disposiciones de la Convemar, existen dos propósitos en la presentación de la información a la CLPC. El primer propósito en la presentación de la información a la CLPC, de acuerdo con el artículo 76(8), es obtener una recomendación de la CLPC respecto de los límites exteriores de la plataforma continental, en caso de que un Estado ribereño desee hacerlo. Esta recomendación se utilizará como base para delinear la plataforma continental y la decisión resultante es oponible a otros Estados.

20. El segundo propósito es permitir a los Estados que pretenden reclamar una plataforma continental cumplir con la "cláusula de extinción" del artículo $4^{\circ}$ del anexo II de la Convemar, el cual requiere que los Estados presenten "las características" de un potencial derecho de plataforma continental a la CLPC dentro de los diez años siguientes a la entrada en vigor de la Convención para ese Estado.

21. En virtud de la decisión adoptada por los Estados partes de la Convemar el 20 de junio de 2008 (SPLOS/183), los Estados pueden presentar "información preliminar" a la CLPC como una forma de cumplir con su obligación del artículo $4^{\circ}$ del anexo II. Esta era una manera de permitir a los Estados, en particular aquellos en vía de desarrollo, que no tuviesen las capacidades técnicas necesarias, cumplir con la "cláusula de extinción" para reclamar una plataforma continental extendida bajo la Convemar, mientras se les proporcionaría tiempo adicional necesario para completar los estudios geológicos y geomorfológicos que prueben la existencia de una plataforma continental extendida. La mayoría comete un error al combinar los propósitos que cumplen estas dos disposiciones de la Convemar. 


\section{$\mathrm{Ne}$ bis in idem y el agotamiento del procedimiento del tratado}

22. Los siete jueces de la opinión disidente conjunta argumentan que, aun si uno aceptara la interpretación de la mayoría de la decisión de 2012, Nicaragua no podría presentarse ante la Corte por segunda vez para intentar remediar la falla procedimental que supuestamente impidió a la Corte en 2012 delimitar la supuesta superposición de su derecho a plataforma continental extendida. Permitir una acción como estas violaría el principio ne bis in idem, según el cual una pretensión repetida es inadmisible sin importar si esta se encuentra protegida por el principio de res judicata.

23. Más aún, la presentación renovada de una pretensión previamente examinada por la Corte debe considerarse inadmisible si esa pretensión se sustenta en el procedimiento del tratado como base para la jurisdicción de la Corte. Por lo tanto, la demanda introductoria de instancia de Nicaragua en el presente asunto no está permitida como resultado del agotamiento del procedimiento del tratado.

\section{Conclusión: la autoridad de la res judicata y la protección de la función judicial}

24. Los siete jueces concluyen su opinión disidente conjunta resaltando la importancia de proteger el carácter definitivo de las decisiones de la Corte, tanto para el funcionamiento eficiente del sistema de solución pacífica de controversias interestatales, como para la protección del Estado demandado respecto de litigios repetidos. En su opinión, un escenario en que los propósitos de la res judicata no sean útiles socavaría la función judicial y la correcta administración de justicia.

25. Nicaragua y Colombia se han encontrado envueltos por varios años en una larga controversia respecto de los respectivos derechos marítimos. Como principal órgano judicial de las Naciones Unidas, la Corte está bien posicionada para solucionar esta controversia. Pero si ella espera seguir siendo considerada como tal, no puede consentir ser vista como un órgano que permite a los Estados presentar la misma controversia una y otra vez. Este escenario limitaría la certeza, estabilidad y carácter definitivo que las decisiones de esta Corte deben proporcionar. 


\section{Opinión separada del juez Owada}

1. El juez Owada ha anexado una opinión separada para discutir dos puntos separados. El primer punto versa sobre la cuestión de la res judicata, que fue formulada por Colombia en su tercera excepción preliminar. El juez Owada concuerda con la decisión de la Corte según la cual la pretensión de Nicaragua de una plataforma continental extendida y su solicitud de delimitación no fueron decididas por la Corte en su fallo de 2012, pero agrega una opinión separada para clarificar su propio razonamiento frente a este punto. El prerrequisito de aplicación del principio res judicata, a saber, la identidad persona, petitium y causa pretendi, no fue disputado por las partes y no está en discusión, sin embargo, el punto de importancia más intrínseca en el presente caso es si la decisión lograda en el fallo de 2012 contiene una determinación final y definitiva por parte de la Corte a la que se le debe otorgar el efecto de resjudicata. En otras palabras, la cuestión se refiere al alcance de la res judicata. Para determinar si la pretensión de Nicaragua fue determinada de forma final y definitiva en el fallo de 2012, se debe examinar el contexto en el cual se desarrolló el aparte operativo del fallo de 2012, así como el razonamiento de la Corte y la estructura general del fallo. Un examen de estos factores, los cuales no fueron abordados de manera adecuada por la Corte en su fallo, lleva a concluir que la pretensión de Nicaragua para que se hiciera una delimitación sobre la clase de su reclamo a una plataforma continental extendida no fue determinada de forma final y definitiva en el fallo de 2012, y, por lo tanto, no se enmarca dentro del alcance de la res judicata. Como resultado, la tercera excepción preliminar de Colombia debe ser rechazada.

2. El segundo punto concierne a la oponibilidad de la Convemar, por parte de Colombia, un Estado no parte, a Nicaragua, un Estado parte. Como el juez Owada concuerda con el razonamiento del fallo al rechazar la quinta excepción preliminar, este asunto solo se eleva como una cuestión de principio porque concierne al derecho aplicable. Es bien establecido que un tratado no crea obligaciones o derechos para un tercer Estado sin su consentimiento, el tratado es res inter alios acta. Como tal, según lo afirmó el fallo de 2012, el derecho aplicable a este caso no es la Convemar — la cual no ha sido ratificada por Colombia-, sino el derecho internacional consuetudinario. Colombia no ha establecido que la disposición relevante del artículo 76 de la Convemar, relativa a las recomendaciones de la CLPC, es una regla del derecho internacional consuetudinario y, sin embargo, Colombia en todo caso intenta invocar esta obligación contra Nicaragua, 
un Estado parte de la Convemar. Aunque el juez Owada concuerda con el razonamiento de la Corte al rechazar la quinta excepción preliminar, parece sugerir que existe una razón adicional para rechazar esta excepción.

\section{Opinión separada del juez Greenwood}

La res judicata tiene efectos sustantivos y no únicamente procedimentales. Si, como Colombia sostiene, el fallo de 2012 decidió que Nicaragua no había probado que tenía un margen continental que se extendía más allá de las 200 millas náuticas desde sus líneas de base, esa decisión hubiera sido res judicata y hubiera impedido a Nicaragua alegar un derecho legal a una plataforma continental extendida vis-a-vis con Colombia no solo en estos procedimientos, sino en cualquier foro. Sin embargo, el fallo de 2012 no decidió eso.

Por cuanto el fallo no dijo nada en relación con el reclamo de Nicaragua con respecto a un área ubicada a más de 200 millas náuticas desde la costa continental de Colombia y a más de 200 millas náuticas desde la costa continental de Nicaragua, no puede surgir ninguna cuestión de res judicata en relación con esa área. Incluso en relación con el área dentro de las 200 millas náuticas contadas desde la costa continental de Nicaragua, el estudio del fallo de 2012 demuestra que la Corte no decidió que Nicaragua debía probar; tampoco revela el fallo ningún análisis por parte de la Corte sobre las fortalezas y debilidades de la evidencia aducida por Nicaragua.

En estas circunstancias, el fallo no puede considerarse un pronunciamiento en el sentido de que Nicaragua no cumplió con su carga de la prueba. Sin embargo, debido a que los argumentos frente a la res judicata en relación con las dos áreas difieren, hubiera sido preferible que la Corte hubiera abordado cada uno de ellos de forma separada en el fallo.

\section{Opinión disidente de la jueza Donoghue}

La jueza Donoghue no concuerda con la interpretación que hace la Corte del subpárrafo dispositivo (3) del fallo en la Controversia territorialy marítima (Nicaragua c. Colombia) —ICJ Reports 2012 (II), p. 719, para. 251(3)—. Como consecuencia, está en desacuerdo con la conclusión a la que llegó la Corte el día de hoy frente a la tercera excepción preliminar de Colombia, con fundamento en la cual Colombia alegó que la doctrina de la res judicata hacía inadmisible la demanda. 
La Corte el día de hoy expresa que en 2012 decidió que la pretensión de Nicaragua no podía ser aceptada porque Nicaragua no había aún efectuado una reclamación ante la Comisión de Límites de la Plataforma Continental en relación con los límites de su margen continental más allá de las 200 millas náuticas. En la medida en que Nicaragua ya ha efectuado esa reclamación, la Corte concluye que la doctrina de la res judicata no le impide pronunciarse sobre la primera pretensión de Nicaragua en el presente caso.

De acuerdo con la jueza Donoghue, sin embargo, en 2012 la Corte tomó una decisión sobre los méritos de la pretensión de Nicaragua. En particular, la Corte decidió que Nicaragua no había probado que su plataforma continental se extendía lo suficiente para superponerse con la titularidad generada por la costa continental de Colombia y, por lo tanto, que no estaba en posición de delimitar según lo solicitó Nicaragua. Esta determinación fue esencial para la decisión de la Corte de no aceptar la reclamación de Nicaragua. Por lo tanto, considera que la doctrina de la res judicata le niega a Nicaragua la oportunidad de probar los mismos hechos por una segunda vez en un segundo caso frente al mismo demandado, y que en esa medida la primera pretensión de Nicaragua es inadmisible.

Sin embargo, la jueza Donoghue observa que el fallo de 2012 no abordó la cuestión de la existencia de una superposición entre la titularidad de Nicaragua y la titularidad generada por las islas de Colombia en el área ubicada más allá de las 200 millas náuticas desde la costa de Nicaragua. La doctrina de res judicata no aplica a esta materia y la primera pretensión de Nicaragua es admisible en esa medida.

Finalmente, la jueza Donoghue presenta las razones por las cuales está en desacuerdo con la interpretación de la Corte en el subpárrafo dispositivo (3) del fallo de 2012.

\section{Declaración del juez Gaja}

La delimitación de la plataforma continental entre Estados con costas opuestas o adyacentes es normalmente difícil en ausencia de la delineación de los límites exteriores de la plataforma continental, tarea que bajo el artículo 76, párrafo 8, de la Convemar, debe hacerse sobre la base de una recomendación de la Comisión de Límites de la Plataforma Continental. De conformidad con el artículo 76, párrafo 10, de la Convemar, una recomendación que establece los límites exteriores de la plataforma continental no prejuzga la cuestión de la delimitación y puede, por lo tanto, adoptarse 
con independencia de la existencia de una disputa de delimitación. La Comisión debe modificar sus reglas de procedimiento y considerar las pretensiones también cuando la delimitación se encuentre bajo controversia.

\section{Declaración del juez Bhandari}

En su declaración, el juez Bhandari recuerda que se ha unido a la opinión disidente que abordó la tercera excepción preliminar de Colombia en relación con la cuestión de la res judicata. El propósito de la presente declaración es presentar comentarios adicionales sobre la quinta excepción preliminar, relativa a la omisión de Nicaragua en obtener una recomendación vinculante por parte de la Comisión de Límites de la Plataforma Continental ('CLPC', por su sigla en inglés). Al concluir que él aceptaría la quinta excepción preliminar de Colombia, el juez Bhandari expresa ocho breves consideraciones. En primer lugar, no hay prueba en el registro de que Nicaragua haya presentado toda la información relevante ante la CLPC, la cual, sin embargo, es la premisa que sustenta la conclusión de la mayoría en este punto. En segundo lugar, ya que la CLPC todavía no ha emitido una recomendación, la Corte no está en posición de especular sobre el momento en que la CLPC podría emitirla. Tercero, el principio de la cortesía interinstitucional exige diferir a la CLPC.

En cuarto lugar, la CLPC es un cuerpo especializado con expertos que cuentan con experiencia práctica, y que están encargados de hacer recomendaciones vinculantes sobre asuntos relativos a la plataforma continental. En quinto lugar, permitir que este caso prosiga a la fase de méritos sin esperar a la recomendación de la CLPC va en contra del razonamiento expuesto en el fallo de 2012. En sexto lugar, ya que Nicaragua es signatario de la Convención de las Naciones Unidas sobre el Derecho del Mar (Convemar) está obligado por sus disposiciones. En séptimo lugar, no debería permitírsele a una nación llevar a cabo una apelación o revisión de facto de un fallo que es final y vinculante entre las partes, en violación del Estatuto de la Corte. Finalmente, permitirle a Nicaragua presentarse ante la Corte sin una recomendación final de la CLPC dejaría a este último órgano sin autoridad alguna.

\section{Declaración del juez Robinson}

He suscrito la opinión disidente conjunta porque, por las razones que presentaré aquí, soy de la opinión de que la tercera excepción preliminar 
de Colombia debe ser aceptada. Escribo esta declaración para elaborar en mayor medida sobre una preocupación específica que emerge del fallo del día de hoy, en donde la mayoría acoge y aplica el dicta contenido en el fallo de 2012 de una forma tal que deroga un principio elemental del derecho de los tratados.

Los tratados son vinculantes para los Estados porque estos han consentido a los primeros. Este consentimiento es una expresión de los principios de soberanía e igualdad entre los Estados. Las obligaciones y derechos bajo un tratado no aplican a actores no estatales a menos de que los Estados partes hubieran tenido esa intención y el Estado no parte consienta, o porque las disposiciones del tratado hacen parte del derecho internacional consuetudinario. Estos principios parecieran haber sido ignorados en la decisión mayoritaria del día de hoy.

La Corte señaló de manera bastante directa en el párrafo 118 de su fallo de 2012 que el derecho aplicable a este caso era el derecho internacional consuetudinario, debido a que Colombia no era parte de la Convemar. El artículo 76(8) de la Convemar y el procedimiento de la CLPC previsto en el anexo 2 son especiales, contractuales y confinados a los Estados partes de la Convemar.

La mayoría leyó el fallo de 2012 en el sentido de imponer un 'prerrequisito' o una 'condición', de conformidad con el artículo 76(8) de la Convemar, para la delimitación de las titularidades sobre la plataforma continental extendida entre Nicaragua y Colombia. En los párrafos 86 y 87 del fallo de hoy, la mayoría consideró que, "como Nicaragua señala que el 24 de junio de 2013 le entregó a la CLPC información 'final”, "en concordancia considera que la condición impuesta por esta en su fallo de 2012 para poder examinar la pretensión contenida en la pretensión final I 3) de Nicaragua ha sido cumplida en el presente caso".

La lógica desarticulada de esta interpretación se discute plenamente en la disidencia conjunta. Debe decirse además que el resultado de la interpretación de la mayoría es la aplicación de un derecho que de manera efectiva es inaplicable entre las partes. A Colombia, un Estado no parte, se le ha otorgado algo que, en mi opinión, es equivalente a un beneficio bajo la Convemar, ya que el artículo 76(8) de la Convemar, que no representa una regla de derecho internacional consuetudinario, ha sido aplicado en relaciones entre Nicaragua y Colombia. Esto genera preguntas sobre la compatibilidad del enfoque de la Corte con el régimen previsto en los artículos 34 y 36 de la Convención de Viena sobre el Derecho de los Tratados (tratados y terceros Estados). 


\section{Declaración del juez ad hoc Brower}

En su declaración, el juez ad hoc Brower concuerda con todos los demás miembros de la Corte en concluir que, en el balance, la Corte tiene jurisdicción sobre la demanda de Nicaragua bajo el Pacto de Bogotá. Él ha emitido una declaración para explicar las dificultades que la Corte necesariamente ha encontrado para aceptar la interpretación de Colombia al párrafo segundo del artículo LVI del Pacto, en particular, dada la ausencia de una guía útil en los travaux préparatoires.

El juez ad hoc Brower observa que el abogado de Nicaragua reconoció durante los procedimientos orales que el segundo párrafo del artículo LVI del Pacto es "superfluo, pero [...] no inefectivo". La alternativa de Nicaragua frente al reconocimiento de la interpretación que hace Colombia de ese párrafo es que no tiene significado de ningún tipo más que dejar constancia, en una manifestación de abundante cuidado, sobre lo que de todas formas sería cierto. La Corte ha estado de acuerdo con Nicaragua, a pesar de que generalmente se inclina a atribuirle un significado a cada una de las disposiciones de un tratado, según lo requiere el principio effet utile.

El juez ad hoc Brower observa que los artículos LVIII y LIX del Pacto, en el contexto de la totalidad del artículo LVI, podrían reflejar de manera colectiva la intención de las partes de que, una vez el Pacto hubiera sido denunciado por una parte, ningún nuevo procedimiento pudiera ser iniciado. También podría argumentarse que el segundo párrafo del artículo LVI tenía el effet utile de dejar claro lo que para ese entonces todavía no se había establecido con claridad por la Corte en el caso Nottebohm - Liechtenstein c. Guatemala), Excepciones preliminares, fallo, ICJ Reports 1953, p. 111—, esto es, que la jurisdicción de la Corte se consolida con la presentación de la demanda y permanece desde ese momento sin importar la terminación subsiguiente del instrumento sobre el cual se basó la jurisdicción. La Corte no ha considerado convincentes ninguno de estos argumentos debido a la total ausencia de una indicación en los muy limitados travaux préparatoires sobre la razón por la que el segundo párrafo fue incluido.

Todo lo que la Corte pudo derivar de la historia de la redacción fue que el mismo lenguaje fue mantenido a lo largo de las diferentes conferencias relevantes y versiones del Pacto en su progreso hasta su adopción. En ninguna parte existe registro que indique por qué lo que se convirtió en el segundo párrafo del artículo LVI del Pacto de Bogotá fue introducido y aceptado de manera repetitiva en el curso de diez años. Claramente, es debido a la ausencia de una tal guía que la Corte se vio obligada a preferir 
una interpretación según la cual el párrafo en cuestión, aunque superfluo, tenía el effet utile de expresar un abundante cuidado, por sobre la más compleja inferencia a contrario.

El juez ad hoc Brower considera que la conclusión de la Corte no es irrazonable y, por lo tanto, no es posible disentir de esta. 